\title{
Thermodynamic Database Update to Model Synthetic Chelating Agents in Soil Systems
}

\author{
Felipe Yunta ${ }^{1, *}$, Sandra López-Rayo ${ }^{2}$ and Juan J. Lucena ${ }^{2}$ \\ ${ }^{1}$ Departamento de Geología y Geoquímica, Facultad de Ciencias, Universidad Autónoma de Madrid, 28049 \\ Madrid, Spain \\ ${ }^{2}$ Departamento de Química Agrícola, Facultad de Ciencias, Universidad Autónoma de Madrid, 28049 Madrid, \\ Spain
}

\begin{abstract}
Polyaminocarboxylate and polyaminophenolcarboxylate chelating agents, of which EDTA and o,o-EDDHA are the most representative, are being profusely studied by our research team for 25 years due to their importance as micronutrient fertilizers used to correct nutritional disorders, and based on their level of impact on crop yields in Mediterranean regions. Recently, new chelating agents have been designed and synthesized; it has been suggested that these agents be included in the current European Directive on Fertilizers. Overall chelating agent properties, including equilibrium in soil based on modeling studies, should be considered when evaluating iron chlorosis correction ability. Chemical speciation programs such as MINTEQA2, and most recently VMinteq, have been successfully used as tools for predicting the behaviors of novel chelating agents in soil-plant systems. Currently, only one polyaminophenolcarboxylate chelating agent (o,o-EDDHA) is available in the VMinteq-compatible database (Lindsay's database), although more than seven have been approved as European fertilizers, which can be used as micronutrient fertilizers. Therefore, the aim of this project was to update the database to include all chelating agents related to $0,0-$ EDDHA and EDTA, whose complete characterization has been performed and is published elsewhere. Once the database is updated, further modeling studies, such as equilibrium studies and adsorption isotherm studies based on solid phase analysis, can be performed to determine fundamental information about and understand the reactivity of these recalcitrant polyaminophenolcarboxylates in soils.
\end{abstract}

Keywords: chelating agents, iron, database, VMinteq, chemical equilibrium program, EDDHA, EDTA, iron chelates, fertilizers.

\section{INTRODUCTION}

Iron chlorosis is a plant nutritional disorder primarily present in alkaline and/or calcareous soils, and it dramatically limits agricultural production in many areas worldwide, with $20 \%$ to $50 \%$ of fruit crops being affected by iron deficiency symptoms in the Mediterranean region. Currently, the most commonly used synthetic $\mathrm{Fe}$ chelates in agricultural practice being used to control against $\mathrm{Fe}$ chlorosis are derived from both polyaminecarboxylic acids (related to ethylenediaminetetraacetic acid - EDTA) and polyaminephenolcarboxylic acids (related to ethylenediaminedi-(o-hydroxyphenylacetic) acid -o,oEDDHA) [1]. New chelating agents have recently been designed and synthesized, some of which have been proposed to be included in the current European Directive on Fertilizers [2-5]. Novel synthesis pathways reported by several authors [6-10] have yield chelating agent standards highly pure for their complete characterization. Three steps have reported the characterization of novel chelating agents [11], including the determination of equilibrium constants (protonation and stability constants), free $\mathrm{Fe}(\mathrm{III})$ activity

*Address corresponding to this author at the Departamento de Geología y Geoquímica, Facultad de Ciencias, Universidad Autónoma de Madrid, 28049 Madrid, Spain; Tel: +34914976265; Fax: +34914976440;

E-mail: felipe.yunta@uam.es and its relationship with complex formation, and species distribution in both hydroponics (nutrient solution) and soil conditions (solid phase as equilibrium controller), which are currently being applied to individually characterize novel chelating agents $[8,9,12,13]$. The last two steps can be performed using the MINTEQA2 [14] or, most recently, the VMinteq [15] software programs to examine speciation. These programs show a strong correlation between modeling results and actual behavior in agronomic conditions. Other similar speciation programs such as GEOCHEMPC [16] or the upgraded version of GEOCHEM-EZ [17] and Phreeqc [18] may be used, as compatible database are used by all of these computational programs. Therefore, new equilibrium figures related to compounds with relevant agronomic or environmental effects (such as is the case for iron chelates) should be made available to the research community by updating the database so that this information can be used in further modeling studies.

Sorption and desorption are key processes that affect the fate of agrochemicals in the soil-water environment, and thus a thorough understanding of adsorption is of central importance for predicting the mobility and availability of synthetic iron chelates in soils. To date, most attempts to model iron chelate adsorption onto soil components (clay, organic matter, 
and iron (hydr)oxides) have involved classical adsorption isotherms $[8,19,20]$. Batch experiments may show that iron chelates related to o,o-EDDHA can chelate the highest amount of iron, regardless of the soil components used as sorbent surfaces. Thus, a large adsorption rate onto ferrihydrite and goethite was observed for meso-o,o-EDDHA, in comparison with the other one diastereoisomer [20]. However, no complexation mechanisms can be proposed given that updated databases are unavailable for adsorption modeling. The examination of chelating agent adsorption mechanisms enables the evaluation and prediction of the rate at which these iron chelates are sorbed by soil solid phases. Currently, several surface complexation models, which are being used as tools to relate adsorption to equilibrium conditions in the aqueous phase [21], are being applied to assess adsorption onto pesticides, which are composed primarily of iron (hydr)oxydes [22] or their contaminants [23]. These adsorption studies can be performed more easily once the corresponding database is updated.

MINTEQA2 Version 3.11 is extremely useful for examining equilibrium relationships in soils and waters; however, some equilibrium relationships are known to be useful in soils, and related media are not included in this version of the software. In 2009, Visual MINTEQ was the second-most used chemical equilibrium software application among researchers. This is likely because significant efforts have been made to maintain an updated database [15]. For many years, researchers examining chemical equilibrium relationships in soils [24] have sought to determine equilibrium constants suitable for use in soil chemistry. Thus, o,o-EDDHA equilibrium constants were compiled by Lindsay (1979) [24], and a specific database was created, which is available for VMinteq. Since that year, the database has not been updated to include novel synthetic chelating agents that can be examined in equilibrium or adsorption studies, even as the list of new chelating agents approved for use as micronutrient fertilizers has grown considerably. For these reasons, the aim of this work was to publish a modified database that includes most of the chelating agent equilibrium constants from our previous publications. Moreover, the proposed updated database was adapted for use with all adsorption models that VMinteq has included in its latest version (VMinteq v 3.0. beta).

\section{EXPERIMENTAL}

\subsection{General Procedures}

Equilibrium constants for most of the chelating agents described herein were determined by our research group $[6,8,9,25]$. Once chelating agents were synthetized, characterization and equilibrium studies of the free ligands, as well as of $\mathrm{Mg}^{2+}, \mathrm{Ca}^{2+}, \mathrm{Cu}^{2+}$, and $\mathrm{Fe}^{3+}$ were performed using methods that are widely implemented for newly synthesized products $[8,9,11$ $13,25]$. Briefly, protonation constants were determined using both spectrophotometric and potentiometric methods. Stability constants for $\mathrm{Ca}^{2+}, \mathrm{Mg}^{2+}, \mathrm{Mn}^{2+}$, and $\mathrm{Zn}^{2+}$ were determined from potentiometric titrations $[25,26]$. A new spectrophotometric method was developed in order to establish the $\mathrm{Fe}^{3+}$ and $\mathrm{Cu}^{2+}$ stability constants with chelating agents [11]. Once stability constants were determined, relative chelating ability in agronomic conditions was measured as free metal activity (pM = - log [M]) using either MINTEQA2 [14] or the updated version of VMinteq [15] speciation programs by modifying the component and thermodynamic databases to define new components and species, respectively.

o,o-EDDHA (ethylenediamine- $N, N$ 'bis (2hydroxyphenyl)acetic acid) (see 1 in Figure 1) and its related chelating agents, including o,o-EDDH4MA (ethylenediamine- $\quad N, N$ 'bis(2-hydroxy-4methylphenyl)acetic acid) (see 4 in Figure 1), 0,0EDDHSA (ethylenediamine- $N, N$ 'bis(2-hydroxy-5sulphonylphenyl)acetic acid) (see 7 in Figure 1), 0,0EDDH5MA (ethylenediamine- $N, N$ 'bis(2-hydroxy-5methylphenyl)acetic acid) (see 6 in Figure 1), p,pEDDHA (ethylenediamine- $N, N$ 'bis (4hydroxyphenyl)acetic acid) (see 3 in Figure 1), and o,0EDDMtxA (ethylenediamine- $N, N$ 'bis (2metoxyphenyl)acetic acid) (see 5 in Figure 1) were synthesized following a new synthetic pathway [6] to assess the effects of either their different substituents, or their positions in the benzene ring of o,o-EDDHA-like chelating agents. Relevant results from this research demonstrated that at least one ortho-hydroxyphenyl group is necessary in the formation of $\mathrm{Fe}^{3+}$ chelates. Thus, o,p-EDDHA (see 2 in Figure 1) was synthetized using two complementary synthesis routes [7], and full characterization was performed [12] .

Additionally, rac-o,o-EDDHA (see A in Figure 2) and meso-0,0-EDDHA (see B in Figure 2) diastereoisomers were obtained [27]. The o,o-EDDH4MA diastereoisomers such as rac-0,0-EDDH4MA and meso-0,0-EDDH4MA were isolated from the 0,0EDDH4MA mixture by precipitation [13].

In the same manner, synthesis, protonation, and $\mathrm{Ca}^{2+}, \mathrm{Mg}^{2+}, \mathrm{Fe}^{3+}$, and $\mathrm{Cu}^{2+}$ stability constants as well as chemical modeling for 0,0-PDDHA (propylenediamine- 


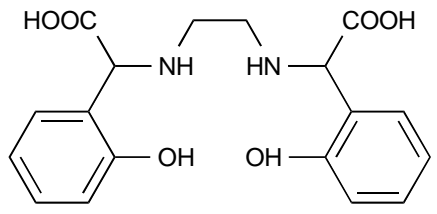

(1) 0,0 -EDDHA

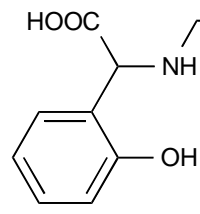

(2) $o, p-\mathrm{EDDHA}$

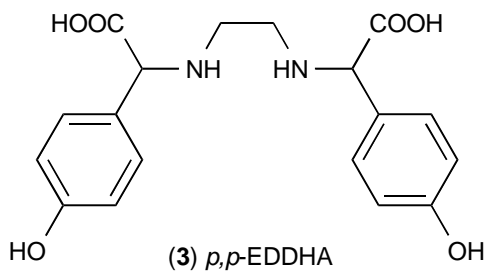

(3) $p, p-E D D H A$

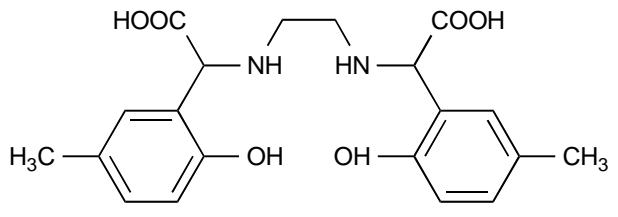

(6) EDD5MA

(4) EDDH4MA

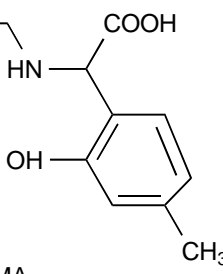

$\mathrm{COOH}$<smiles>COc1ccccc1C(NCCNC(C(=O)O)c1ccccc1OC)C(=O)O</smiles>

(5) EDDMtxA<smiles>NC(C(=O)O)c1ccc(O)cc1</smiles>

$\mathrm{OH}$

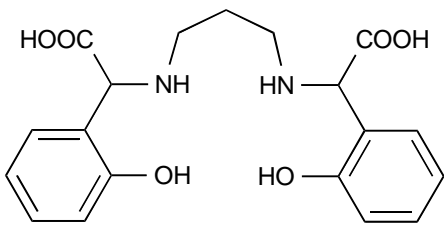

(8) PDDHA

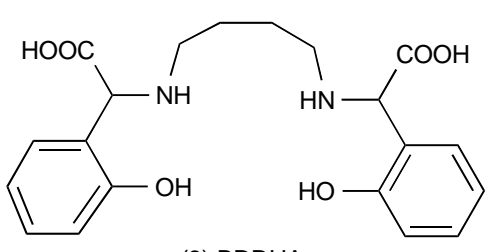

(9) BDDHA

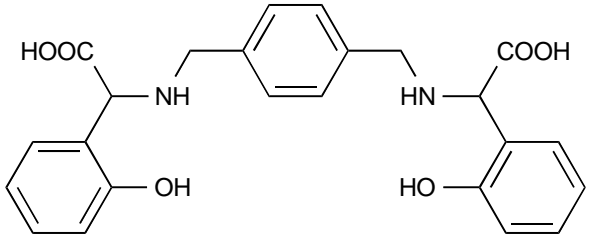

(10) XDDHA

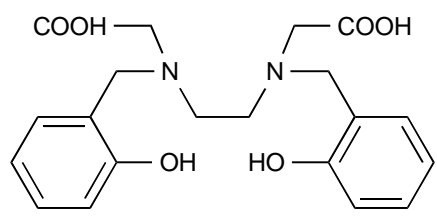

(11) HBED<smiles>Cc1ccc(CN(CCN(CC(=O)O)Cc2ccc(C)cc2O)CC(=O)O)c(O)c1</smiles>

(12) HJB

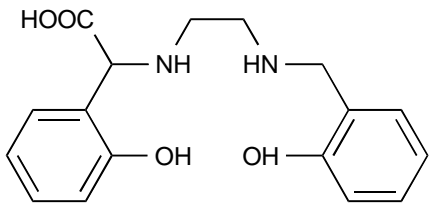

(13) DCHA

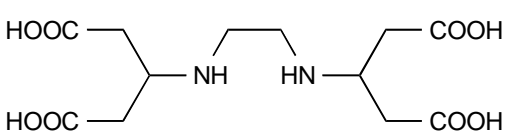

(14) EDTA<smiles>O=C(O)CC(CC(=O)O)N[C@@H](CC(=O)O)C(=O)O</smiles>

(15) IDHA

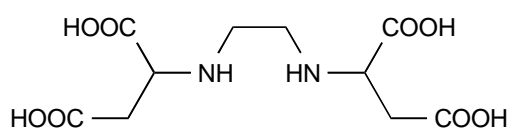

(16) EDDS

Figure 1: Structure of the new chelating agents included in updated Lindsay's database.

\section{$N, N$ '-bis(o-hydroxyphenyl)acetic acid) (see 8 in Figure} 1), o,o-BDDHA (butylenediamine- $N, N$ '-bis ( $O$ hydroxyphenyl)acetic acid) (see 9 in Figure 1), and o,0XDDHA ( $p$-xylylenediamine- $N, N$ '-bis(o-hydroxyphenyl) acetic acid) (see 10 in Figure 1) were determined and published [28]. These chelating agents were designed to quantify the effect of the length of the alkyl chain connecting the hydoxyphenylglycine moieties on metal chelate stability.
HBED (N,N'-bis(2-hydroxyphenyl)ethylendiamine$\mathrm{N}, \mathrm{N}^{\prime}$-diacetic acid) (see 11 in Figure 1) was initially designed for treating diseases related to iron overload [29] because it is forming the most stable iron chelate $[29,30]$. The chelating agent $\mathrm{N}, \mathrm{N}^{\prime}$-bis(2-hydroxy-5methylbenzyl)ethylenediamine- $\mathrm{N}, \mathrm{N}^{\prime}$-diacetic acid (HJB) (see 13 in Figure 1) is related to HBED, but has methy groups bound to the phenolates in the para position. HJB possesses the same donor groups and a structure 

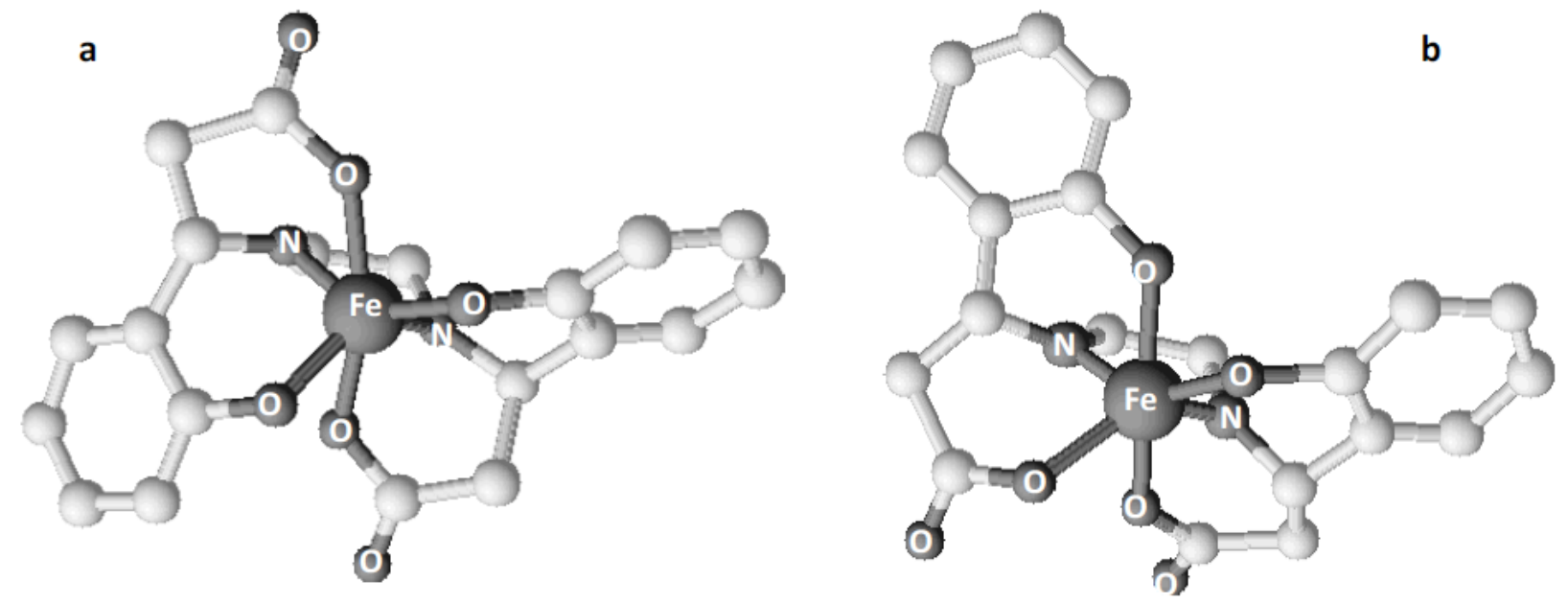

Figure 2: Spatial structures of rac-o,o-EDDHA/Fe ${ }^{3+}(\mathbf{a})$, meso-o,o-EDDHA/Fe ${ }^{3+}(\mathbf{b})$.

similar to that of HBED. HJB synthesis produces a purer product than Fe-o,o-EDDHA because neither optical isomers nor other byproducts are formed [10]. Stability constants for HJB were determined, and theoretical modeling for HBED and HJB in agronomic conditions using the VMinteq speciation program was conducted [8].

Another pentacoordinate chelating agent related to HBED has been designed. Following the synthesis of DCHA (2-(2-((2-hydroxybenzyl)amino)ethylamino)-2-(2hydroxyphenyl)acetic acid)) (see 12 in Figure 1), its protonation, $\mathrm{Ca}^{2+}, \mathrm{Mg}^{2+}, \mathrm{Fe}^{3+}$, and $\mathrm{Cu}^{2+}$ stability constants, and its ability to maintain iron in solution under different agronomic conditions were determined using the modeling VMinteq speciation program [9]. However, it should be noted that most of the chelating agents described above, including the well-known and widely used EDTA (ethylenediaminetetraacetic acid) (see 14 in Figure 1), are recalcitrants in soils and waters. Currently, concerns for the environmental risk of their application in soils [31] are increasing. New products, such as the biodegradable $N-(1,2-$ dicarboxyethyl)-D,L aspartic acid (IDHA) (see 15 in Figure 1) and ethylenediaminedisuccinic acid (EDDS) (see 16 in Figure 1) have been proposed for use as chelating agents for micronutrient fertilizers [25, 32-35].

\subsection{Equilibrium Constant Transformation}

All equilibrium constants were calculated as mixed constants $\left(K^{\mathrm{m}}\right)$ in which all terms are given in concentrations, except $\mathrm{H}^{+}$and $\mathrm{OH}^{-}$, which are given in activities. For redox conditions, the parameter pe was used. The conversion to concentration constants $\left(K^{c}\right)$, in which all reactants and products are expressed in terms of concentrations except pe at some specified ionic strength, were found using the activity coefficients from the Davies' equation (eq. 1):

$K_{0.1}^{C}=K_{0.1}^{m} \cdot \gamma_{H}$

and were reported elsewhere $[8,9,12,13,25,28]$

However, additional conversions to activity constants $\left(\mathrm{K}^{0}\right)$ in which all of the terms are expressed in activities must be conducted in order to enter these equilibrium constants into thermodynamic database by applying eq. 2 :

$K^{0}=K^{C} \cdot \frac{\gamma_{\text {products }}}{\gamma_{\text {reactans }}}$

Activity coefficients $\left(\gamma_{i}\right)$ for the involved ions were determined using the equation proposed by Davies [36] (see eq. 3), taking into account both ion charges and ionic strength:

$\log \gamma_{i}=-A Z_{i}^{2}\left(\frac{\mu^{1 / 2}}{1+\mu^{1 / 2}}-0.3 \mu\right)$

where $\mathrm{A}=0.509$ for water at $25^{\circ} \mathrm{C}$

\subsection{Database Updates}

The VMinteq program functions based on a fourroot database. Three of these, comp.vdb, thermo.vdb, and type6.vdb, are related to components, aqueous equilibrium, and solids, respectively. In this work, the first two ones were expanded by adhering either each novel chelating agent as single component with its specific ID number or each equilibrium constant (log $\mathrm{K}^{0}$ ) already either experimentally determined or bibliographically available. 


\section{RESULTS AND DISCUSSION}

Complete component and thermodynamic databases can be found in the attached supporting information.

\subsection{Component Database}

The component database including new chelating agents is shown in Table 1. The component database was updated with 18 new synthetic chelating agents and an additional 0,0-EDDHA. The entire modified component database is available in the separate supporting information file. Required parameters, such as molecular weight for fully deprotonated chelating agents and their charges, were recorded as well. An additional o,o-EDDHA (ID\# 920) has been recorded as a new component in the database in addition to the existing o,o-EDDHA (ID\# 954) in Lindsay's database [24]. This o,o-EDDHA component corresponds to the data obtained using a novel organic synthesis pathway [6]. Four new isomers related to o,o-EDDHA were included: two positional isomers, o,p-EDDHA (ID\# 931) and p,p-EDDHA (ID\# 923), and two diastereisomers, rac-o,o-EDDHA (ID\# 921) and meso-o,o-EDDHA (ID\# 922). Moreover, a chelating agent related to o,o-
EDDHA but with two methoxy groups on the benzene rings rather than two phenolic groups were synthesized to show that phenolic groups in the ortho position are necessary for binding $\mathrm{Fe}^{3+}$ [13]. Additional methyl groups on the benzene ring define two positional isomers, o,o-EDDH4MA (ID\# 924) and o,o-EDDH5MA (ID\# 927), both of which are currently authorized for use as chelating agents for micronutrients [2-5]. For o,o-EDDH4MA, two corresponding diastereomers (raco,o-EDDH4MA; ID\# 925 and meso-o,o-EDDH4MA; ID\# 926) were included because they appear to be the main constituents of the commercial Fe-0,0-EDDH4MA fertilizer. 0,0-EDDHSA (ID\# 934) is another authorized chelating agent used as iron fertilizer. 0,0-PDDHA (ID\#928), o,o-BDDHA (ID\# 930), and o,o-XDDHA (ID\# 929) were shown to have a similar iron chelation rate to that of $0,0-E D D H A$, and they can be readily synthetized [6].

HBED (ID\# 935) is one of the first synthetic chelating agents studied [30] and applied for medical purposes. Recently, a novel synthesis pathway for HBED was published [10] for obtaining highly pure products. Chelating agents related to HBED, such as the methyl-substituted HJB (ID\# 938) and the

Table 1: Chelating Agents Entered in Component Database (comp.vdb)

\begin{tabular}{|c|c|c|c|}
\hline Component \# & Chelating Agent & Charge & $\mathrm{MW}\left(\mathrm{g} \cdot \mathrm{mol}^{-1}\right)$ \\
\hline 920 & o,o-EDDHA & -4 & 356.4 \\
\hline 921 & rac-o,o-EDDHA & -4 & 356.4 \\
\hline 922 & meso-o,o-EDDHA & -4 & 356.4 \\
\hline 923 & p,p-EDDDHA & -4 & 356.4 \\
\hline 924 & o,o-EDDH4MA & -4 & 384.4 \\
\hline 925 & rac-EDDH4MA & -4 & 384.4 \\
\hline 926 & meso-EDDH4MA & -4 & 384.4 \\
\hline 927 & o,o-EDDH5MA & -4 & 384.4 \\
\hline 928 & o,0-PDDHA & -4 & 370.4 \\
\hline 929 & 0,0-XDDHA & -4 & 432.5 \\
\hline 930 & o,o-ButDDHA & -4 & 384.4 \\
\hline 931 & o,p-EDDHA & -4 & 356.4 \\
\hline 932 & o,o-EDDMetxA & -2 & 386.5 \\
\hline 934 & o,o-EDDHSA & -6 & 514.4 \\
\hline 935 & HBED & -4 & 384.4 \\
\hline 936 & IDHA & -4 & 245.1 \\
\hline 937 & $\mathrm{DCHA}$ & -3 & 316.3 \\
\hline 938 & HJB & -4 & 412.5 \\
\hline 939 & EDDS & -4 & 292.0 \\
\hline
\end{tabular}


pentacoordinated DCHA (ID\# 937) were recently characterized $[8,9]$.

IDHA (ID\# 936) and EDDS (ID\# 937) were included in the component database as biodegradable alternatives to EDTA. They are being fully characterized for validation as authorized chelating agents for micronutrient fertilizers $[32,33,34]$.

\subsection{Thermodynamic Database}

New species for each chelating agent are shown in Tables 2 through 20. All information entered into the thermodynamic database for each chelating agent is shown, including species ID number, equilibrium reaction, charge, molecular weight, and corresponding activity constants. The entire thermodynamic database with all species can be found in the supporting information section. The species ID number corresponding to each equilibrium constant was assigned in accordance with the main components involved in each equilibrium reaction. Each species ID number is defined by seven digits, which are then configured in three-digit sets. The first digit set corresponds with either the hydrogen component (component ID\# 330 when protonation constants are defined) or the metal for which the formation constant was determined (i.e., \#281 for $\mathrm{Fe}^{3+}$, \#231 for $\mathrm{Cu}^{2+}$, \#470 for $\mathrm{Mn}^{2+}$, \#950 for $\mathrm{Zn}^{2+}$, \#470 for $\mathrm{Mn}^{2+}$, \#150 for $\mathrm{Ca}^{2+}$, and $\# 460$ for $\mathrm{Mg}^{2+}$ ). The second three digits indicate the chelating agent as assigned in the component database description. The last digit is used to differentiate between species involving the same chelating agent and metal, but that have different numbers of hydrogen or hydroxyl constituents.

3.2.1. Equilibrium Constants for $0,0-E D D H A$, raco,o-EDDHA, meso-o,o-EDDHA, p,p-EDDHA, o,oEDDH4MA, rac-o,o-EDDH4MA, meso-o,oEDDH4MA, 0,0-EDDH5MA, 0,0-EDDHSA, and 0,0EDDMtxA

Protonation and stability constants for $0,0-E D D H A$ (see Table 2), rac-o,o-EDDHA (see Table 3), mesoo,o-EDDHA (see Table 4), p,p-EDDHA (see Table 5),

Table 2: Equilibrium constants for 0,0-EDDHA. Equilibrium constants are shown in terms of activity constants ( $\mathrm{K}^{0}$ ). Other mandatory parameters such as charge and Molecular Weight (MW) have to be entered in thermodynamic database

O,0-EDDHA

\begin{tabular}{|c|c|c|c|c|}
\hline \multicolumn{5}{|c|}{ О,o-EDDHA } \\
\hline Specie ID\# & Specie Equilibrium & $\mathrm{K}^{\circ}$ & Charge & MW \\
\hline 3309202 & {$\left[H_{2} L\right] /[H]^{2}[L]$} & 24.17 & -2 & 358.4 \\
\hline 3309203 & {$\left[H_{3} L\right] /[H]^{3}[L]$} & 33.26 & -1 & 359.4 \\
\hline 1509201 & {$[\mathrm{CaL}] /[\mathrm{Ca}][\mathrm{L}]$} & 9.00 & -2 & 396.5 \\
\hline 1509202 & {$[\mathrm{CaHL}] /[\mathrm{Ca}][\mathrm{H}][L]$} & 18.91 & -1 & 397.5 \\
\hline 1509203 & {$\left[\mathrm{CaH}_{2} \mathrm{~L}\right] /[\mathrm{Ca}][\mathrm{H}]^{2}[\mathrm{~L}]$} & 28.30 & 0 & 398.5 \\
\hline 4609201 & {$[M g L] /[M g][L]$} & 11.47 & -2 & 380.7 \\
\hline 2819202 & {$[\mathrm{FeHL}] /[\mathrm{Fe}][\mathrm{H}][\mathrm{L}]$} & 39.67 & 0 & 413.3 \\
\hline 2819203 & {$[\mathrm{FeOHL}] /[\mathrm{Fe}][\mathrm{H}]^{1}[\mathrm{~L}]$} & 25.80 & -2 & 429.3 \\
\hline 2319201 & {$[\mathrm{CuL}] /[\mathrm{Cu}][L]$} & 26.84 & -2 & 419.9 \\
\hline 2319202 & {$[\mathrm{CuHL}] /[\mathrm{Cu}][\mathrm{H}][\mathrm{L}]$} & 34.75 & -1 & 420.9 \\
\hline 2319203 & {$\left[\mathrm{CuH}_{2} L\right] /[\mathrm{Cu}][\mathrm{H}]^{2}[\mathrm{~L}]$} & 39.66 & 0 & 421.9 \\
\hline 4709201 & {$[M n L] /[M n][L]$} & 11.28 & -2 & 415.1 \\
\hline 4709202 & {$[\mathrm{MnHL}] /[\mathrm{Mn}][\mathrm{H}][\mathrm{L}]$} & 22.03 & -1 & 416.1 \\
\hline 4709203 & {$\left[\mathrm{MnH}_{2} L\right] /[M n][H]^{2}[L]$} & 29.46 & 0 & 417.1 \\
\hline
\end{tabular}


Table 3: Equilibrium constants for rac-0,0-EDDHA. Equilibrium constants are shown in terms of activity constants $\left(\mathrm{K}^{0}\right)$. Other mandatory parameters such as charge and Molecular Weight (MW) have to be entered in thermodynamic database

rac-0,0-EDDHA

\begin{tabular}{|c|c|c|c|c|}
\hline Specie ID\# & Specie Equilibrium & Ko & Charge & MW \\
\hline 3309211 & {$[H L] /[H][L]$} & 12.74 & -3 & 357.4 \\
\hline 3309213 & {$\left[H_{3} L\right] /[H]^{3}[L]$} & 33.29 & -1 & 359.4 \\
\hline 3309214 & {$\left[H_{4} L\right] /[H]^{4}[L]$} & 39.78 & 0 & 360.4 \\
\hline 1509212 & {$[\mathrm{CaHL}] /[\mathrm{Ca}][\mathrm{H}][\mathrm{L}]$} & 19.56 & -1 & 397.5 \\
\hline 1509213 & {$\left[\mathrm{CaH}_{2} \mathrm{~L}\right] /[\mathrm{Ca}][\mathrm{H}]^{2}[\mathrm{~L}]$} & 29.23 & 0 & 398.5 \\
\hline 4609211 & {$[M g L] /[M g][L]$} & 11.84 & -2 & 380.7 \\
\hline 2819211 & {$[\mathrm{Fe} L] /[\mathrm{Fe}][L]$} & 38.43 & -1 & 412.3 \\
\hline
\end{tabular}

Table 4: Equilibrium constants for meso-0,0-EDDHA. Equilibrium constants are shown in terms of activity constants $\left(\mathrm{K}^{\mathrm{b}}\right)$. Other mandatory parameters such as charge and Molecular Weight (MW) have to be entered in thermodynamic database

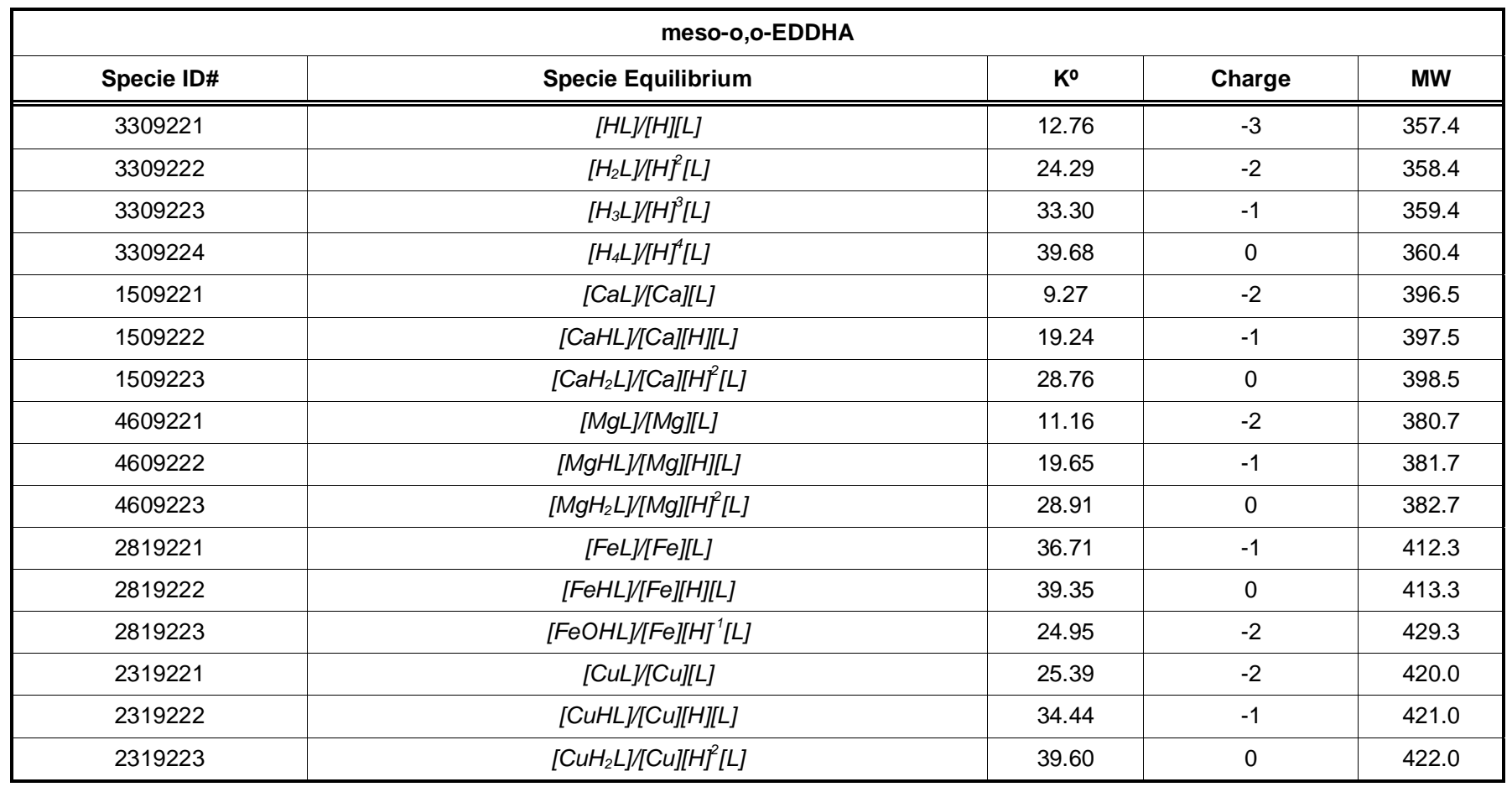

0,0-EDDHA4MA (see Table 6), rac-0,0-EDDH4MA (see Table 7), meso-o,o-EDDH4MA (see Table 8), o,oEDDMtxA (see Table 9), o,o-EDDH5MA (see Table 10), and o,o-EDDHSA (see Table 11) were determined and are discussed extensively elsewhere [13,25]. All published equilibrium constants (including protonation and formation constants) are expressed in terms of concentration constants specifying ionic strength $(\mu=$ $0.1 \mathrm{M})$ and temperature $\left(25^{\circ} \mathrm{C}\right)$. Therefore, transformation into activity constants should be 
Table 5: Equilibrium constants for p,p-EDDHA. Equilibrium constants are shown in terms of activity constants $\left(K^{0}\right)$. Other mandatory parameters such as charge and Molecular Weight (MW) have to be entered in thermodynamic database

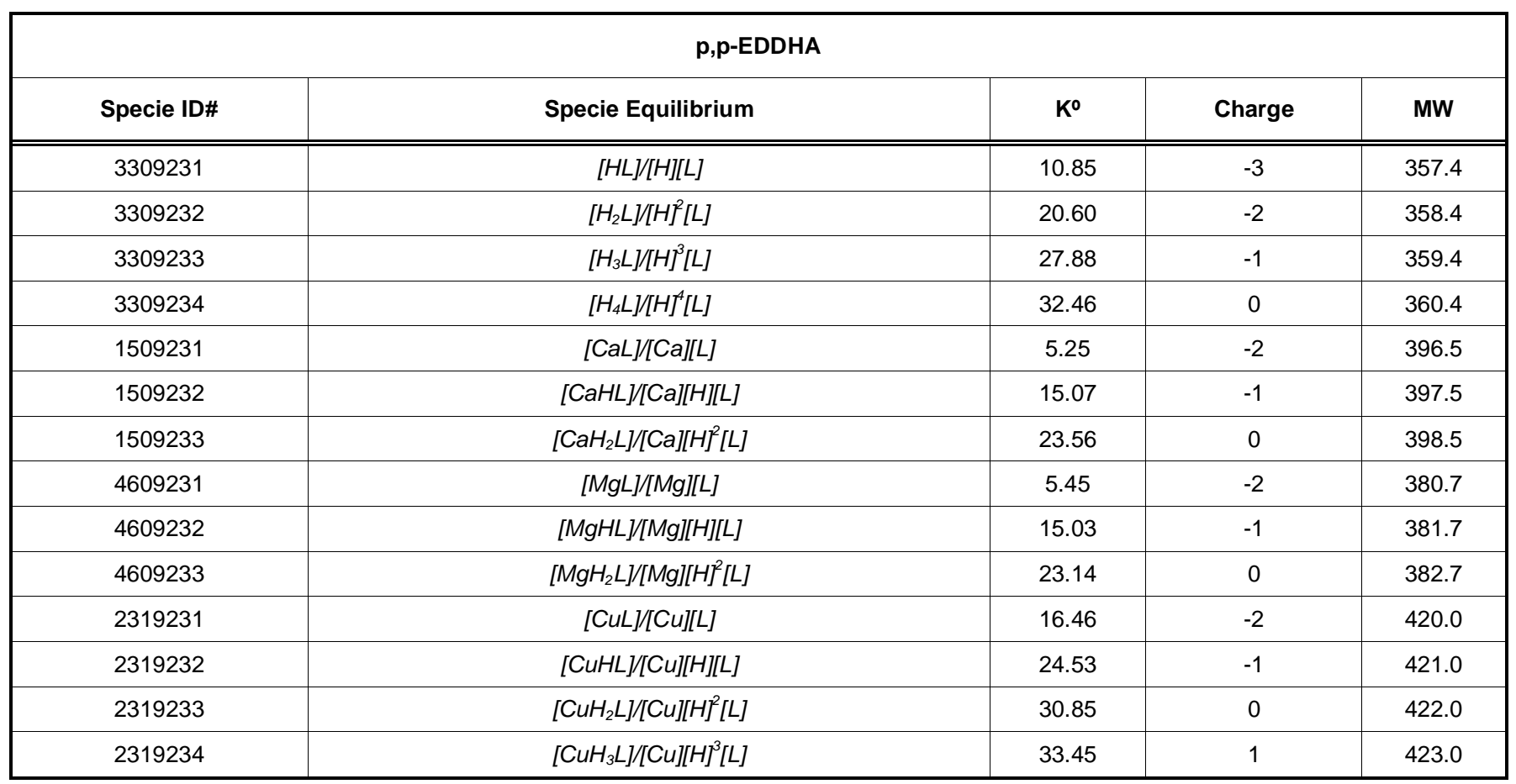

Table 6: Equilibrium constants for o,o-EDDH4MA. Equilibrium constants are shown in terms of activity constants $\left(\mathrm{K}^{0}\right)$. Other mandatory parameters such as charge and Molecular Weight (MW) have to be entered in thermodynamic database

\section{0,0-EDDH4MA}

\begin{tabular}{|c|c|c|c|c|}
\hline Specie ID\# & Specie Equilibrium & Ko & Charge & MW \\
\hline 3309241 & {$[H L] /[H][L]$} & 12.49 & -3 & 385.4 \\
\hline 3309243 & {$\left[H_{3} L\right] /[H]^{3}[L]$} & 32.78 & -1 & 387.4 \\
\hline 3309244 & {$\left[H_{4} L\right] /[H]^{4}[L]$} & 39.39 & 0 & 388.4 \\
\hline 1509242 & {$[\mathrm{CaHL}] /[\mathrm{Ca}][\mathrm{H}][\mathrm{L}]$} & 18.00 & -1 & 425.5 \\
\hline 1509243 & {$\left[\mathrm{CaH}_{2} L\right] /[\mathrm{Ca}][\mathrm{H}]^{2}[\mathrm{~L}]$} & 26.93 & 0 & 426.5 \\
\hline 4609241 & {$[M g L] /[M g][L]$} & 9.71 & -2 & 408.7 \\
\hline 4609242 & {$[\mathrm{MgHL}] /[\mathrm{Mg}][\mathrm{H}][\mathrm{L}]$} & 19.20 & -1 & 409.7 \\
\hline 2819243 & {$[\mathrm{FeOHL}] /[\mathrm{Fe}][\mathrm{H}]^{1}[\mathrm{~L}]$} & 24.95 & -2 & 457.3 \\
\hline 2319241 & {$[\mathrm{CuL}] /[\mathrm{Cu}][\mathrm{L}]$} & 25.65 & -2 & 448.0 \\
\hline 2319242 & {$[\mathrm{CuHL}] /[\mathrm{Cu}][\mathrm{H}][\mathrm{L}]$} & 33.20 & -1 & 449.0 \\
\hline 2319243 & {$\left[\mathrm{CuH}_{2} L\right] /[\mathrm{Cu}][\mathrm{H}]^{2}[\mathrm{~L}]$} & 38.43 & 0 & 450.0 \\
\hline
\end{tabular}


Table 7: Equilibrium constants for rac-0,0-EDDH4MA. Equilibrium constants are shown in terms of activity constants $\left(K^{0}\right)$. Other mandatory parameters such as charge and Molecular Weight (MW) have to be entered in thermodynamic database

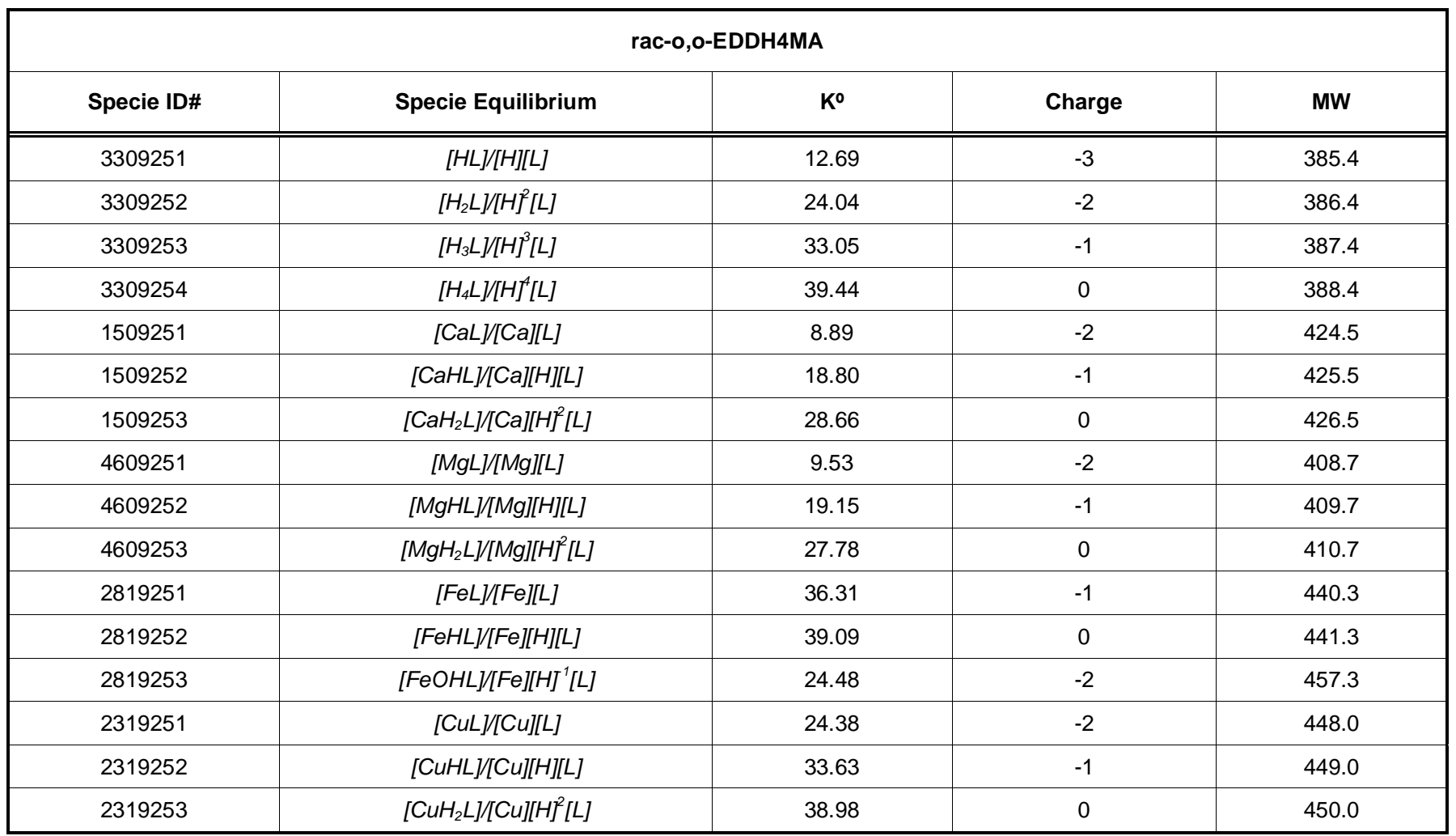

Table 8: Equilibrium constants for meso-0,0-EDDH4MA. Equilibrium constants are shown in terms of activity constants $\left(\mathrm{K}^{0}\right)$. Other mandatory parameters such as charge and Molecular Weight (MW) have to be entered in thermodynamic database

meso-0,0-EDDH4MA

\begin{tabular}{|c|c|c|c|c|}
\hline Specie ID\# & Specie Equilibrium & Ko & Charge & MW \\
\hline 3309261 & {$[H L] /[H][L]$} & 12.83 & -3 & 385.4 \\
\hline 3309263 & {$\left[H_{3} L\right] /[H]^{3}[L]$} & 33.37 & -1 & 387.4 \\
\hline 3309264 & {$\left[H_{4} L\right] /[H]^{4}[L]$} & 39.94 & 0 & 388.4 \\
\hline 1509262 & {$[\mathrm{CaHL}] /[\mathrm{Ca}][\mathrm{H}][\mathrm{L}]$} & 19.03 & -1 & 425.5 \\
\hline 1509263 & {$\left[\mathrm{CaH}_{2} L\right] /[\mathrm{Ca}][\mathrm{H}]^{2}[\mathrm{~L}]$} & 28.67 & 0 & 426.5 \\
\hline 4609261 & {$[M g L] /[M g][L]$} & 11.37 & -2 & 408.7 \\
\hline 4609262 & {$[M g H L] /[M g][H][L]$} & 20.02 & -1 & 409.7 \\
\hline 2819263 & {$[\mathrm{FeOHL}] /[\mathrm{Fe}][\mathrm{H}]^{1}[L]$} & 25.59 & -2 & 457.3 \\
\hline 2319261 & {$[\mathrm{CuL}] /[\mathrm{Cu}][\mathrm{L}]$} & 26.18 & -2 & 448.0 \\
\hline 2319262 & {$[\mathrm{CuHL}] /[\mathrm{Cu}][\mathrm{H}][\mathrm{L}]$} & 34.52 & -1 & 448.0 \\
\hline 2319263 & {$\left[\mathrm{CuH}_{2} L\right] /[\mathrm{Cu}][\mathrm{H}]^{2}[\mathrm{~L}]$} & 39.56 & 0 & 449.0 \\
\hline
\end{tabular}


Table 9: Equilibrium constants for o,o-EDDMetxA. Equilibrium constants are shown in terms of activity constants $\left(\mathrm{K}^{0}\right)$. Other mandatory parameters such as charge and Molecular Weight (MW) have to be entered in thermodynamic database

o,o-EDDMetxA

\begin{tabular}{|c|c|c|c|c|}
\hline Specie ID\# & Specie Equilibrium & $\mathrm{K}^{\circ}$ & Charge & MW \\
\hline 3309321 & {$[H L] /[H][L]$} & 8.04 & -1 & 387.5 \\
\hline 1509321 & {$[\mathrm{CaL}] /[\mathrm{Ca}][\mathrm{L}]$} & 4.05 & 0 & 426.6 \\
\hline 1509322 & {$[\mathrm{CaHL}] /[\mathrm{Ca}][\mathrm{H}][\mathrm{L}]$} & 11.50 & 1 & 427.6 \\
\hline 4609322 & {$[M g H L] /[M g][H][L]$} & 11.72 & 1 & 411.8 \\
\hline 4609323 & {$\left[\mathrm{MgH}_{2} L\right] /[M g][H]^{2}[L]$} & -3.92 & -1 & 426.8 \\
\hline 2319321 & {$[\mathrm{CuL}] /[\mathrm{Cu}][\mathrm{L}]$} & 16.15 & 0 & 426.6 \\
\hline 2319322 & {$[\mathrm{CuHL}] /[\mathrm{Cu}][\mathrm{H}][\mathrm{L}]$} & 24.51 & 1 & 450.1 \\
\hline
\end{tabular}

Table 10: Equilibrium constants for o,o-EDDH5MA. Equilibrium constants are shown in terms of activity constants $\left(K^{0}\right)$. Other mandatory parameters such as charge and Molecular Weight (MW) have to be entered in thermodynamic database

0,0-EDDH5MA

\begin{tabular}{|c|c|c|c|c|}
\hline Specie ID\# & Specie Equilibrium & $\mathrm{K}^{\circ}$ & Charge & MW \\
\hline 3309271 & {$[H L] /[H][L]$} & 12.75 & -3 & 385.4 \\
\hline 3309272 & {$\left[H_{2} L\right] /[H]^{2}[L]$} & 24.17 & -2 & 386.4 \\
\hline 3309273 & {$\left[H_{3} L\right] /[H]^{3}[L]$} & 33.31 & -1 & 387.4 \\
\hline 3309274 & {$\left[H_{4} L\right] /[H]^{4}[L]$} & 40.08 & 0 & 388.4 \\
\hline 1509273 & {$\left[\mathrm{CaH}_{2} L\right] /[\mathrm{Ca}][\mathrm{H}]^{2}[\mathrm{~L}]$} & 28.58 & 0 & 426.5 \\
\hline 4609271 & {$[M g L] /[M g][L]$} & 9.54 & -2 & 408.7 \\
\hline 4609272 & {$[\mathrm{MgHL}] /[\mathrm{Mg}][\mathrm{H}][L]$} & 19.02 & -1 & 409.7 \\
\hline 2819273 & {$[\mathrm{FeOHL}] /[\mathrm{Fe}][\mathrm{H}]^{1}[\mathrm{~L}]$} & 24.12 & -2 & 457.3 \\
\hline 2319271 & {$[\mathrm{CuL}] /[\mathrm{Cu}][\mathrm{L}]$} & 25.17 & -2 & 448.0 \\
\hline 2319272 & {$[\mathrm{CuHL}] /[\mathrm{Cu}][\mathrm{H}][\mathrm{L}]$} & 34.35 & -1 & 449.0 \\
\hline 2319273 & {$\left[\mathrm{CuH}_{2} L\right] /[\mathrm{Cu}][\mathrm{H}]^{2}[\mathrm{~L}]$} & 39.72 & 0 & 450.0 \\
\hline
\end{tabular}

conducted to be entered into the thermodynamic database. With the exception of o,o-EDDMtxA, which bears two uncharged methoxy groups, all chelating agents are hexadentate with two phenolate $\left(K_{1}^{H}\right.$ and
$K_{2}^{H}$ ), two nitrogen $\left(K_{3}^{H}\right.$ and $\left.K_{4}^{H}\right)$, and two carboxylate $\left(K_{5}^{H}\right.$ and $K_{6}^{H}$ ) groups. The methyl group in the benzene ring may slightly increase the basicity of the 
phenol. The effect of the sulfonic groups in increasing the acidity of the phenolic groups is reflected in the values of all protonation constants for 0,0-EDDHSA. The magnitudes of the $\mathrm{Mg}^{2+}$ stability constants are higher than those of $\mathrm{Ca}^{2+}$ for all of these chelating agents due to the ligand architecture and metal properties discussed previously [13]. The predominant species with $\mathrm{Fe}^{3+}$ involves coordination with the nitrogen atoms, the carboxylic oxygens, and the phenolate groups ( $\mathrm{FeL}^{-}$), except for p,p-EDDHA and o,o-EDDMtxA, which are not able to form the chelate. The protonated $(\mathrm{FeHL})$ and hydroxylated $\left(\mathrm{FeOHL}^{2-}\right)$ species are predominant at below $\mathrm{pH} 3$ and above $\mathrm{pH}$ 10 , respectively. Similar bonding has been observed for $0,0-E D D H A / \mathrm{Mn}^{2+}$ and $0,0-E D D H A / \mathrm{Zn}^{2+}$ chelates, although the axial donor groups of the organic compound interact weakly with the metal ion [25].

Regarding to $\mathrm{Cu}^{2+}$ species, at neutral $\mathrm{pH}$ or below, coordination only occurs with the nitrogens, the carboxylic oxygens, and with two molecules of water $\left(\mathrm{MH}_{2} \mathrm{~L}\right)$. For p,p-EDDHA and o,o-EDDMtxA, these are the only possible ways of binding $\mathrm{Cu}^{2+}$ due to the absence of ortho-hydroxy groups. Furthermore, for these chelating agents, other $\mathrm{Cu}^{2+}$ stability constants must exclusively involve water molecule binding to the metal $\left(\mathrm{MHL}^{-}\right.$and $\mathrm{ML}^{2-}$ ). For the remaining chelating agents, a new complex is formed as $\mathrm{pH}$ increases. This complex involves the coordination of the $\mathrm{Cu}^{2+}$ by the phenol groups $\left(\mathrm{ML}^{2-}\right)$. Finally, species $\mathrm{MHL}^{-}$appears at intermediate $\mathrm{pH}$ values.

\subsubsection{Equilibrium Constants for 0,0-PDDHA, o,o- $B D D H A$, and 0,0-XDDHA}

The protonation and stability constants of $0,0-$ PDDHA (see Table 12), o,o-BDDHA (see Table 13), and $0,0-X D D H A$ (see Table 14) were reported elsewhere [28]. As the length of the tether chain

Table 11: Equilibrium constants for o,o-EDDHSA. Equilibrium constants are shown in terms of activity constants ( $\mathrm{K}^{0}$ ). Other mandatory parameters such as charge and Molecular Weight (MW) have to be entered in thermodynamic database

\begin{tabular}{|c|c|c|c|c|}
\hline \multicolumn{5}{|c|}{ o,o-EDDHSA } \\
\hline Specie ID\# & Specie Equilibrium & $K^{\circ}=$ & Charge & MW \\
\hline 3309341 & {$[H L] /[H][L]$} & 11.71 & -5 & 515.4 \\
\hline 3309342 & {$\left[H_{2} L\right] /[H]^{2}[L]$} & 21.68 & -4 & 516.4 \\
\hline 3309343 & {$\left[H_{3} L\right] /[H]^{3}[L]$} & 29.99 & -3 & 517.4 \\
\hline 3309344 & {$\left[H_{4} L\right] /[H]^{4}[L]$} & 36.52 & -2 & 518.4 \\
\hline 3309345 & {$\left[H_{5} L\right] /[H]^{5}[L]$} & 39.58 & -1 & 519.4 \\
\hline 3309346 & {$\left[H_{6} L\right] /[H]^{6}[L]$} & 41.30 & 0 & 520.4 \\
\hline 1509341 & {$[\mathrm{CaL}] /[\mathrm{Ca}][\mathrm{L}]$} & 7.97 & -4 & 554.5 \\
\hline 1509342 & {$[\mathrm{CaHL}] /[\mathrm{Ca}][\mathrm{H}][\mathrm{L}]$} & 16.57 & -3 & 555.5 \\
\hline 1509343 & {$\left[\mathrm{CaH}_{2} \mathrm{~L}\right] /[\mathrm{Ca}][\mathrm{H}]^{2}[\mathrm{~L}]$} & 25.82 & -2 & 556.5 \\
\hline 1509344 & {$\left[\mathrm{Ca}_{2} L\right] /[\mathrm{Ca}]^{2}[L]$} & 9.56 & -2 & 594.6 \\
\hline 4609341 & {$[M g L] /[M g][L]$} & 9.52 & -4 & 538.7 \\
\hline 4609342 & {$[M g H L] /[M g][H][L]$} & 17.71 & -3 & 539.7 \\
\hline 4609343 & {$\left[\mathrm{MgH}_{2} L\right] /[\mathrm{Mg}][\mathrm{H}]^{2}[\mathrm{~L}]$} & 25.50 & -2 & 540.7 \\
\hline 4609344 & {$\left[M g_{2} L\right] /[M g]^{2}[L]$} & 11.36 & -2 & 563.0 \\
\hline 2819341 & {$[\mathrm{Fe} L] /[\mathrm{Fe}][L]$} & 36.64 & -3 & 570.3 \\
\hline 2819342 & {$[\mathrm{FeHL}] /[\mathrm{Fe}][\mathrm{H}][L]$} & 39.13 & -2 & 571.3 \\
\hline 2819343 & {$\left[\mathrm{FeH}_{2} L\right] /[\mathrm{Fe}][\mathrm{H}]^{2}[\mathrm{~L}]$} & 41.07 & -1 & 572.3 \\
\hline 2819344 & {$[\mathrm{FeOHL}] /[\mathrm{Fe}][\mathrm{H}]^{1}[L]$} & 24.91 & -4 & 587.3 \\
\hline 2319341 & {$[\mathrm{CuL}] /[\mathrm{Cu}][L]$} & 24.19 & -4 & 578.0 \\
\hline 2319342 & {$[\mathrm{CuHL}] /[\mathrm{Cu}][\mathrm{H}][\mathrm{L}]$} & 33.04 & -3 & 579.0 \\
\hline 2319343 & {$\left[\mathrm{CuH}_{2} L\right] /[\mathrm{Cu}][\mathrm{H}]^{2}[L]$} & 38.05 & -2 & 580.0 \\
\hline 2319344 & {$\left[\mathrm{CuH}_{3} \mathrm{~L}\right] /[\mathrm{Cu}][\mathrm{H}]^{3}[\mathrm{~L}]$} & 39.98 & -1 & 581.0 \\
\hline
\end{tabular}


increases, i.e., from two (o,o-EDDHA) to four methylene units (o,o-BDDHA), the two amino groups become more independent from each other and there is less charge repulsion between them. This fact is reflected in the values of $\log K_{4}^{H}$ for 0,0-PDDHA, 0,0$\mathrm{BDDHA}$, and $0,0-\mathrm{XDDHA}$, which are higher than those of o,o-EDDHA (Tables 12, 13, and 14, respectively).

Table 12: Equilibrium constants for o,o-PDDHA. Equilibrium constants are shown in terms of activity constants $\left(\mathrm{K}^{0}\right)$. Other mandatory parameters such as charge and Molecular Weight (MW) have to be entered in thermodynamic database

0,0-PDDHA

\begin{tabular}{|c|c|c|c|c|}
\hline \multicolumn{5}{|c|}{ O,O-PDDHA } \\
\hline Specie ID\# & Specie Equilibrium & Ko & Charge & MW \\
\hline 3309281 & {$[H L] /[H][L]$} & 13.03 & -3 & 371.4 \\
\hline 3309282 & {$\left[H_{2} L\right] /[H]^{2}[L]$} & 24.75 & -2 & 372.4 \\
\hline 3309283 & {$\left[H_{3} L\right] /[H]^{3}[L]$} & 33.97 & -1 & 373.4 \\
\hline 3309284 & {$\left[H_{4} L\right] /[H]^{4}[L]$} & 41.25 & 0 & 374.4 \\
\hline 1509281 & {$[\mathrm{CaL}] /[\mathrm{Ca}][\mathrm{L}]$} & 7.88 & -2 & 410.5 \\
\hline 1509282 & {$[\mathrm{CaHL}] /[\mathrm{Ca}][\mathrm{H}][\mathrm{L}]$} & 18.57 & -1 & 411.5 \\
\hline 1509283 & {$\left[\mathrm{CaH}_{2} L\right] /[\mathrm{Ca}][\mathrm{H}]^{2}[\mathrm{~L}]$} & 28.22 & 0 & 412.5 \\
\hline 4609281 & {$[M g L] /[M g][L]$} & 10.52 & -2 & 394.7 \\
\hline 4609282 & {$[M g H L] /[M g][H][L]$} & 19.47 & -1 & 395.7 \\
\hline 4609283 & {$\left[M g H_{2} L\right] /[M g][H]^{2}[L]$} & 27.92 & 0 & 396.7 \\
\hline 2819281 & {$[\mathrm{FeL}] /[\mathrm{Fe}][L]$} & 36.11 & -1 & 426.3 \\
\hline 2819282 & {$[\mathrm{FeHL}] /[\mathrm{Fe}][\mathrm{H}][L]$} & 38.62 & 0 & 427.3 \\
\hline 2819283 & {$[\mathrm{FeOHL}][\mathrm{Fe}][\mathrm{H}]^{1}[L]$} & 23.88 & -2 & 443.3 \\
\hline 2319281 & {$[\mathrm{CuL}] /[\mathrm{Cu}][L]$} & 24.02 & -2 & 434.0 \\
\hline 2319282 & {$[\mathrm{CuHL}] /[\mathrm{Cu}][\mathrm{H}][L]$} & 33.87 & -1 & 435.0 \\
\hline 2319283 & {$\left[\mathrm{CuH}_{2} L\right] /[\mathrm{Cu}][H]^{2}[L]$} & 41.23 & 0 & 436.0 \\
\hline
\end{tabular}

Table 13: Equilibrium constants for o,o-BDDHA. Equilibrium constants are shown in terms of activity constants $\left(\mathrm{K}^{0}\right)$. Other mandatory parameters such as charge and Molecular Weight (MW) have to be entered in thermodynamic database

0,0-BDDHA

\begin{tabular}{|c|c|c|c|c|}
\hline \multicolumn{5}{|c|}{ 0,0-BDDHA } \\
\hline Specie ID\# & Specie Equilibrium & Ko & Charge & MW \\
\hline 3309302 & {$\left[H_{2} L\right] /[H]^{2}[L]$} & 24.35 & -2 & 386.4 \\
\hline 3309303 & {$\left[H_{3} L\right] /[H]^{3}[L]$} & 33.51 & -1 & 387.4 \\
\hline 1509302 & {$[\mathrm{CaHL}] /[\mathrm{Ca}][\mathrm{H}][\mathrm{L}]$} & 18.45 & -1 & 425.6 \\
\hline 1509303 & {$\left[\mathrm{CaH}_{2} \mathrm{~L}\right] /[\mathrm{Ca}][\mathrm{H}]^{2}[\mathrm{~L}]$} & 27.82 & 0 & 426.6 \\
\hline 4609301 & {$[M g L] /[M g][L]$} & 9.23 & -2 & 408.7 \\
\hline 4609302 & {$[M g H L] /[M g][H][L]$} & 18.29 & -1 & 409.7 \\
\hline 4609303 & {$\left[\mathrm{MgH}_{2} L\right] /[M g][H]^{2}[L]$} & 27.49 & 0 & 410.7 \\
\hline 2319301 & {$[\mathrm{CuL}] /[\mathrm{Cu}][\mathrm{L}]$} & 21.23 & -2 & 448.0 \\
\hline 2319302 & {$[\mathrm{CuHL}] /[\mathrm{Cu}][\mathrm{H}][\mathrm{L}]$} & 30.82 & -1 & 449.0 \\
\hline 2319303 & {$\left[\mathrm{CuH}_{2} L\right] /[\mathrm{Cu}][\mathrm{H}]^{2}[\mathrm{~L}]$} & 37.74 & 0 & 450.0 \\
\hline
\end{tabular}


Table 14: Equilibrium constants for 0,0-XDDHA. Equilibrium constants are shown in terms of activity constants $\left(\mathrm{K}^{0}\right)$. Other mandatory parameters such as charge and Molecular Weight (MW) have to be entered in thermodynamic database

\begin{tabular}{|c|c|c|c|c|}
\hline \multicolumn{5}{|c|}{ 0,0-XDDHA } \\
\hline Specie ID\# & Specie Equilibrium & Ko & Charge & MW \\
\hline 3309291 & {$[H L] /[H][L]$} & 12.56 & -3 & 433.5 \\
\hline 3309292 & {$\left[H_{2} L\right] /[H]^{2}[L]$} & 24.06 & -2 & 434.5 \\
\hline 3309293 & {$\left[H_{3} L\right] /[H]^{3}[L]$} & 32.99 & -1 & 435.5 \\
\hline 3309294 & {$\left[H_{4} L\right] /[H]^{4}[L]$} & 40.10 & 0 & 436.5 \\
\hline 1509291 & {$[\mathrm{CaL}] /[\mathrm{Ca}][\mathrm{L}]$} & 7.76 & -2 & 472.6 \\
\hline 1509292 & {$[\mathrm{CaHL}] /[\mathrm{Ca}][\mathrm{H}][\mathrm{L}]$} & 18.69 & -1 & 473.6 \\
\hline 1509293 & {$\left[\mathrm{CaH}_{2} L\right] /[\mathrm{Ca}][\mathrm{H}]^{2}[\mathrm{~L}]$} & 27.42 & 0 & 474.6 \\
\hline 4609291 & {$[M g L] /[M g][L]$} & 9.06 & -2 & 456.8 \\
\hline 4609292 & {$[M g H L] /[M g][H][L]$} & 18.73 & -1 & 457.8 \\
\hline 4609293 & {$\left[\mathrm{MgH}_{2} L\right] /[M g][H]^{2}[L]$} & 27.21 & 0 & 458.8 \\
\hline 2819291 & {$[\mathrm{Fe} L] /[\mathrm{Fe}][L]$} & 32.70 & -1 & 488.4 \\
\hline 2819292 & {$[\mathrm{FeHL}] /[\mathrm{Fe}][\mathrm{H}][\mathrm{L}]$} & 36.90 & 0 & 489.4 \\
\hline 2319291 & {$[\mathrm{CuL}] /[\mathrm{Cu}][\mathrm{L}]$} & 19.23 & -2 & 496.1 \\
\hline 2319292 & {$[\mathrm{CuHL}] /[\mathrm{Cu}][\mathrm{H}][\mathrm{L}]$} & 28.73 & -1 & 497.1 \\
\hline
\end{tabular}

The magnitudes of $\mathrm{Mg}^{2+}$ stability constants for EDDHA and its analogs were higher than those for $\mathrm{Ca}^{2+}$ across all products examined [13].

For the $\mathrm{Fe}^{+3}$ formation constants for these types of chelating agents, the predominant species and $\mathrm{pH}$ levels are the same as those described for 0,0-EDDHA. When $\mathrm{Cu}^{+2}$ stability constants were compared, it was found that as the length between the two amino groups increases, stability of the $\mathrm{Cu}^{2+}$ chelate decreases.

\subsubsection{Equilibrium Constants of o,p-EDDHA}

Protonation and stability constants for o,p-EDDHA are shown in Table 15. All equilibrium constants entered into the database were determined by our research group $[12,25]$ based on a o,p-EDDHA using a novel synthesis pathway [7]. Protonation and formation constants with the most relevant metals for agricultural proposes have been described elsewhere [12,25], using a previously validated method [8], and described by other authors [37]. No dissociation constants of carboxylic groups from o,o-EDDHA and p,p-EDDHA (see Tables 2 and 5, respectively) were determined because precipitate was found when the $\mathrm{pH}$ was lower than 5; however, the corresponding dissociation constants could be readily determined in o,p-EDDHA since no precipitation was observed.
Regarding the formation constants with $\mathrm{Mg}^{+2}$ and $\mathrm{Ca}^{+2}$ metals, the same trend that was previously observed and explained for all phenolic ligands was also found for o,p-EDDHA. The main o,p-EDDHA/Fe ${ }^{3+}$ and $o, p-E D D H A / \mathrm{Cu}^{2+}$ formation constants are shown in Table 15. Three $\mathrm{FeHL} \cdot \mathrm{H}_{2} \mathrm{O}, \mathrm{Fe}(\mathrm{LH})(\mathrm{OH})^{-}$, and $\mathrm{FeLOH}^{2-}$ species are formed since a water molecule occupies the vacant position left by para-hydroxy phenolate.

For $\mathrm{Cu}^{2+}$, the tendency is similar to that of $\mathrm{Ca}^{2+}$ and $\mathrm{Mg}^{2+}$ described above, since $\mathrm{Cu}^{2+}$ has four main coordination positions in a square arrangement. In the [o,p-EDDHA/Cu] species, the metal is bonded to one carboxylate and one phenolate. The other two species $\left(\mathrm{CuHL}^{-}\right.$and $\left.\mathrm{CuL}^{2-}\right)$ are similar o,o-EDDHA/Cu ${ }^{2+}$ because the copper is coordinated with two amino groups and one or two carboxylate groups.

The o,p-EDDHA/ $/ \mathrm{Mn}^{2+}$ and o,p-EDDHA $/ \mathrm{Zn}^{2+}$ species present similar structures to those of $\mathrm{Fe}^{3+}$, with a weak bond in the axial donor group as observed for 0,0EDDHA.

\subsubsection{Equilibrium Constants for HBED, HJB, and DCHA}

Equilibrium constants for HBED (11 in Figure 1), HJB (12 in Figure 1), and DCHA (13 in Figure 1) are shown in Tables 16, 17, and 18, respectively. 
Table 15: Equilibrium constants for o,p-EDDHA. Equilibrium constants are shown in terms of activity constants $\left(K^{0}\right)$. Other mandatory parameters such as charge and Molecular Weight (MW) have to be entered in thermodynamic database

\section{o,p-EDDHA}

\begin{tabular}{|c|c|c|c|c|}
\hline Specie ID\# & Specie Equilibrium & Кo & Charge & MW \\
\hline 3309311 & {$[H L] /[H][L]$} & 12.04 & -3 & 357.4 \\
\hline 3309312 & {$\left[H_{2} L\right] /[H]^{2}[L]$} & 22.86 & -2 & 358.4 \\
\hline 3309313 & {$\left[H_{3} L\right] /[H]^{3}[L]$} & 31.94 & -1 & 359.4 \\
\hline 3309314 & {$\left[H_{4} L\right] /[H]^{4}[L]$} & 38.35 & 0 & 360.4 \\
\hline 3309315 & {$\left[H_{5} L\right] /[H]^{5}[L]$} & 40.92 & 1 & 361.4 \\
\hline 3309316 & {$\left[H_{6} L\right] /[H]^{6}[L]$} & 42.20 & 2 & 362.4 \\
\hline 1509311 & {$[\mathrm{CaL}] /[\mathrm{Ca}][\mathrm{L}]$} & 5.83 & -2 & 396.4 \\
\hline 1509312 & {$[\mathrm{CaHL}] /[\mathrm{Ca}][\mathrm{H}][L]$} & 16.41 & -1 & 397.4 \\
\hline 1509313 & {$\left[\mathrm{CaH}_{2} \mathrm{~L}\right] /[\mathrm{Ca}][\mathrm{H}]^{2}[\mathrm{~L}]$} & 25.59 & 0 & 398.4 \\
\hline 4609311 & {$[M g L] /[M g][L]$} & 7.36 & -2 & 380.7 \\
\hline 4609312 & {$[\mathrm{MgHL}] /[\mathrm{Mg}][\mathrm{H}][L]$} & 17.69 & -1 & 381.7 \\
\hline 4609313 & {$\left[\mathrm{MgH}_{2} \mathrm{~L}\right] /[\mathrm{Mg}][\mathrm{H}]^{2}[\mathrm{~L}]$} & 26.18 & 0 & 382.7 \\
\hline 2819311 & {$[\mathrm{FeL}] /[\mathrm{Fe}][\mathrm{L}]$} & 31.29 & -1 & 412.3 \\
\hline 2819312 & {$[\mathrm{FeHL}] /[\mathrm{Fe}][\mathrm{H}][L]$} & 37.81 & 0 & 413.3 \\
\hline 2819313 & {$\left[\mathrm{FeH}_{2} \mathrm{~L}\right][\mathrm{Fe}][\mathrm{H}]^{2}[\mathrm{~L}]$} & 40.13 & 1 & 414.3 \\
\hline 2819314 & {$[\mathrm{FeOHL}] /[\mathrm{Fe}][\mathrm{H}]^{1}[L]$} & 21.59 & -2 & 429.3 \\
\hline 2319311 & {$[\mathrm{CuL}] /[\mathrm{Cu}][\mathrm{L}]$} & 23.45 & -2 & 419.9 \\
\hline 2319312 & {$[\mathrm{CuHL}] /[\mathrm{Cu}][\mathrm{H}][\mathrm{L}]$} & 33.10 & -1 & 420.9 \\
\hline 2319313 & {$\left[\mathrm{CuH}_{2} L\right] /[\mathrm{Cu}][\mathrm{H}]^{2}[L]$} & 38.52 & 0 & 421.9 \\
\hline 2319314 & {$\left[\mathrm{CuH}_{3} L\right] /[\mathrm{Cu}][\mathrm{H}]^{3}[L]$} & 40.50 & 1 & 422.9 \\
\hline 4709311 & {$[M n L] /[M n][L]$} & 9.81 & -2 & 415.1 \\
\hline 4709312 & {$[M n H L] /[M n][H][L]$} & 20.5 & -1 & 416.1 \\
\hline 9509311 & {$[Z n L] /[Z n][L]$} & 14.15 & -2 & 425.5 \\
\hline 9509312 & {$[Z n H L] /[Z n][H][L]$} & 24.81 & -1 & 426.5 \\
\hline 9509313 & 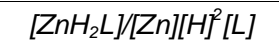 & 32.46 & 0 & 427.5 \\
\hline
\end{tabular}

Table 16: Equilibrium constants for HBED. Equilibrium Constants are Shown in Terms of Activity Constants $\left(K^{0}\right)$. Other mandatory parameters such as charge and Molecular Weight (MW) have to be entered in thermodynamic database

\begin{tabular}{|c|c|c|c|c|}
\hline \multicolumn{5}{|c|}{ HBED } \\
\hline Specie ID\# & Specie Equilibrium & Ko & Charge & MW \\
\hline 3309351 & {$[H L] /[H][L]$} & 13.32 & -3 & 385.4 \\
\hline 3309352 & {$\left[H_{2} L\right] /[H]^{2}[L]$} & 24.96 & -2 & 386.4 \\
\hline 3309353 & {$\left[H_{3} L\right] /[H]^{3}[L]$} & 33.71 & -1 & 387.4 \\
\hline 3309354 & {$\left[H_{4} L\right] /[H]^{4}[L]$} & 38.56 & 0 & 388.4 \\
\hline 1509351 & {$[\mathrm{CaL}] /[\mathrm{Ca}][\mathrm{L}]$} & 11.00 & -2 & 424.4 \\
\hline 1509352 & {$[\mathrm{CaHL}] /[\mathrm{Ca}][\mathrm{H}][L]$} & 20.12 & -1 & 425.4 \\
\hline 1509353 & {$\left[\mathrm{CaH}_{2} L\right] /[\mathrm{Ca}][\mathrm{H}]^{2}[\mathrm{~L}]$} & 27.83 & 0 & 426.4 \\
\hline 4609351 & {$[M g L] /[M g][L]$} & 12.22 & -2 & 408.7 \\
\hline 4609352 & {$[M g H L] /[M g][H][L]$} & 20.80 & -1 & 409.7 \\
\hline 4609353 & {$\left[\mathrm{MgH}_{2} \mathrm{~L}\right] /[\mathrm{Mg}][\mathrm{H}]^{2}[\mathrm{~L}]$} & 28.02 & 0 & 410.7 \\
\hline 2819351 & {$[F e L] /[F e][L]$} & 42.25 & -1 & 440.3 \\
\hline 2319351 & {$[\mathrm{CuL}] /[\mathrm{Cu}][\mathrm{L}]$} & 23.09 & -2 & 448.0 \\
\hline 2319352 & {$[\mathrm{CuHL}] /[\mathrm{Cu}][\mathrm{H}][L]$} & 32.15 & -1 & 449.0 \\
\hline 2319353 & {$\left[\mathrm{CuH}_{2} \mathrm{~L}\right] /[\mathrm{Cu}][\mathrm{H}]^{2}[\mathrm{~L}]$} & 37.54 & 0 & 450.0 \\
\hline
\end{tabular}


Table 17: Equilibrium constants for HJB. Equilibrium constants are shown in terms of activity constants $\left(\mathrm{K}^{0}\right)$. Other mandatory parameters such as charge and Molecular Weight (MW) have to be entered in thermodynamic database

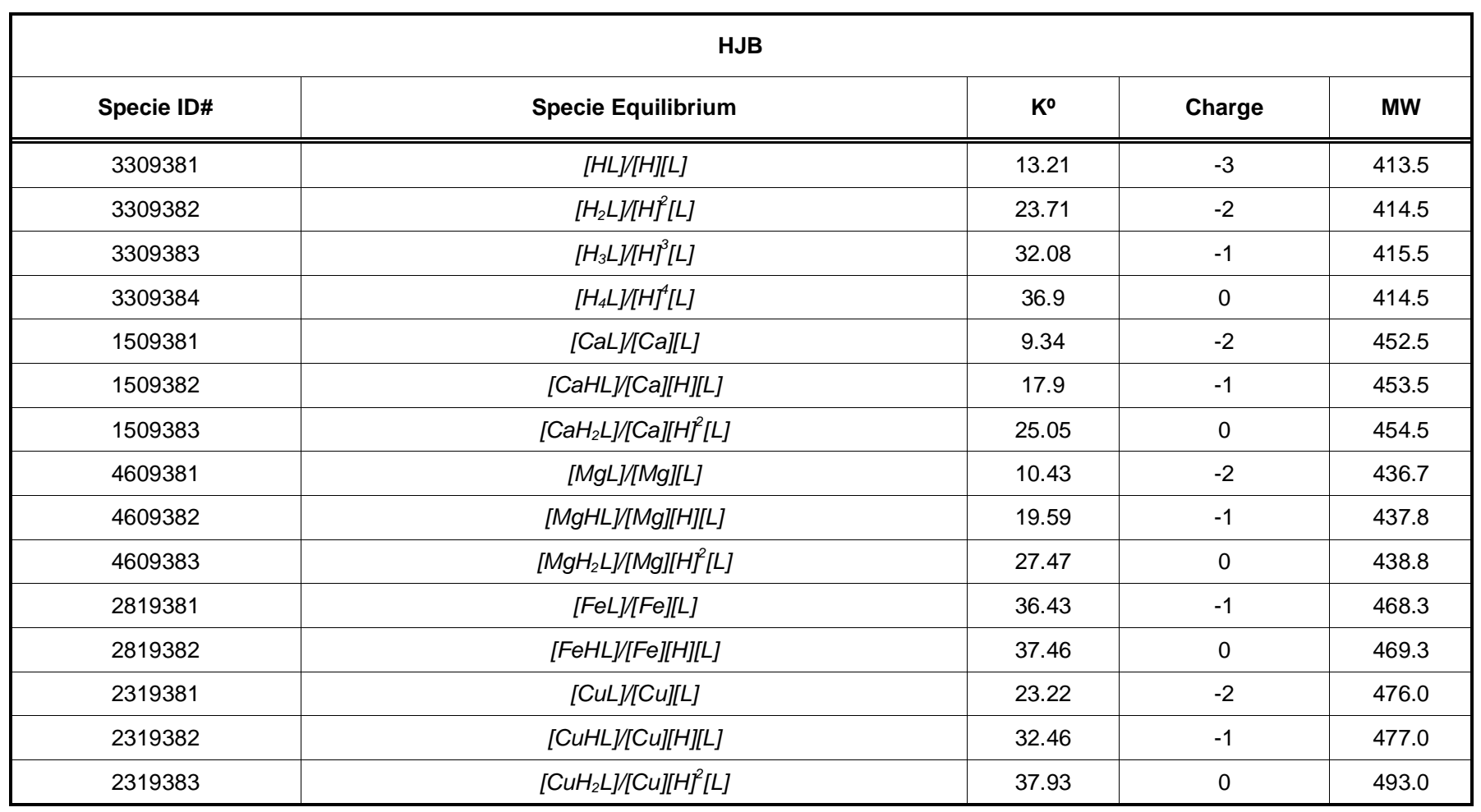

Table 18: Equilibrium constants for DCHA. Equilibrium constants are shown in terms of activity constants $\left(\mathrm{K}^{0}\right)$. Other mandatory parameters such as charge and Molecular Weight (MW) have to be entered in thermodynamic database

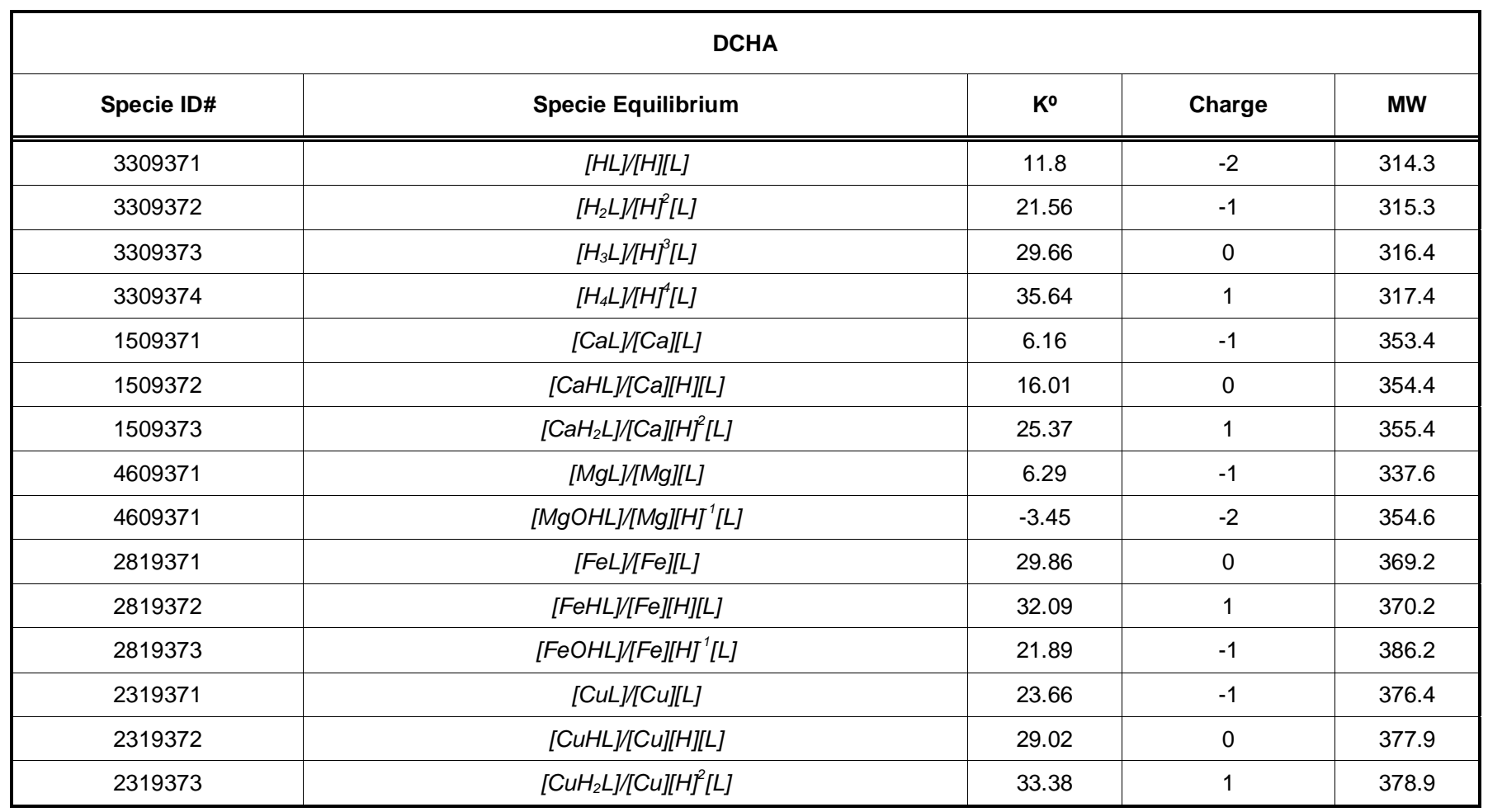


Constants for HBED were bibliographically obtained $[29,30]$ in terms of their concentration; they were then converted to activity constants as previously described. Equilibrium constants for HJB and DCHA were determined, and their constants were entered into the database $[8,9]$.

HJB has a first protonation constant similar to of its analog HBED. However, the second protonation constant is notably the lowest, possibly due to the methyl group acting as a substituent on the benzene ring. The remaining protonation constants are similar to those of HBED.

$\mathrm{HJB} / \mathrm{Ca}^{2+}$ and $\mathrm{HJB} / \mathrm{Mg}^{2+}$ stability constants are generally lower than those of HBED complexes, likely due to the influence of the methyl groups in the benzene rings. The formed $\mathrm{HJB} / \mathrm{Fe}^{3+}$ species are similar to those of the $0,0-E D D H A / F e^{3+}$ species, involving (in the case of FeL species) the amino nitrogen atoms, carboxylic oxygens, and phenolate groups.
Regarding the $\mathrm{HJB} / \mathrm{Cu}^{2+}$ formation constants (Table 17), $\mathrm{CuH}_{2} \mathrm{~L}, \mathrm{CuHL}$, and CuL stability constants were identified and determined. Corresponding species may be similar to o,o-EDDHA/ $\mathrm{Cu}^{2+}$.

Because the charge of DCHA $\left(\mathrm{L}^{3-}\right)$ is lower than those of o,o-EDDHA and o,p-EDDHA $\left(\mathrm{L}^{4-}\right)$, the acidity of the phenolate and amine groups is higher in DCHA, resulting in a lower affinity towards protons (see Tables 18, 1, and 6 for protonation constants for DCHA, 0,0EDDHA, and o,p-EDDHA, respectively), as already described previously [26] for other similar chelating agents but with different overall charges.

As expected from previous results, the magnitudes of the DCHA/ $\mathrm{Mg}^{2+}$ stability constants are higher than those of DCHA/Ca ${ }^{2+}$ (see Table 18).

DCHA ligand can complex $\mathrm{Cu}^{2+}$ with two phenolate and two amine groups. As has been extensively described [9], the lack of the second carboxylate group in the DCHA ligand leads to decreased stability of $\mathrm{DCHA} / \mathrm{Cu}^{2+}$ at low $\mathrm{pH}$. Thus, a water molecule will

Table 19: Equilibrium constants for IDHA. Equilibrium constants are shown in terms of activity constants $\left(\mathrm{K}^{0}\right)$. Other mandatory parameters such as charge and Molecular Weight (MW) have to be entered in thermodynamic database

\begin{tabular}{|c|c|c|c|c|}
\hline \multicolumn{5}{|c|}{ IDHA } \\
\hline Specie ID\# & Specie Equilibrium & Кo & Charge & MW \\
\hline 3309361 & {$[H L] /[H][L]$} & 11.38 & -3 & 246.1 \\
\hline 3309362 & {$\left[H_{2} L\right] /[H]^{2}[L]$} & 16.57 & -2 & 247.1 \\
\hline 3309363 & {$\left[H_{3} L\right] /[H]^{3}[L]$} & 20.53 & -1 & 248.1 \\
\hline 3309364 & {$\left[H_{4} L\right] /[H]^{4}[L]$} & 23.17 & 0 & 249.1 \\
\hline 3309365 & {$\left[H_{5} L\right] /[H]^{5}[L]$} & 24.69 & 1 & 250.1 \\
\hline 2819361 & {$[F e L] /[\mathrm{Fe}][L]$} & 16.43 & -1 & 300.9 \\
\hline 2819362 & {$[\mathrm{FeHL}] /[\mathrm{Fe}][\mathrm{H}][L]$} & 20.53 & 0 & 301.9 \\
\hline 2819363 & {$[\mathrm{FeOHL}] /[\mathrm{Fe}][H]^{1}[L]$} & 10.7 & -2 & 299.9 \\
\hline 2319361 & {$[\mathrm{CuL}] /[\mathrm{Cu}][\mathrm{L}]$} & 14.59 & -2 & 308.6 \\
\hline 2319362 & {$[\mathrm{CuHL}] /[\mathrm{Cu}][\mathrm{H}][\mathrm{L}]$} & 19.41 & -1 & 309.6 \\
\hline 2319363 & {$\left[\mathrm{CuH}_{2} L\right] /[\mathrm{Cu}][\mathrm{H}]^{2}[L]$} & 22.75 & 0 & 310.6 \\
\hline 2319364 & {$[\mathrm{CuOHL}] /[\mathrm{Cu}][\mathrm{H}]^{1}[\mathrm{~L}]$} & 3.55 & -3 & 307.6 \\
\hline 4709361 & {$[M n L] /[M n][L]$} & 8.97 & -2 & 300.0 \\
\hline 9509361 & {$[Z n L] /[Z n][L]$} & 11.86 & -2 & 310.5 \\
\hline 9509362 & {$[\mathrm{ZnHL}] /[\mathrm{Zn}][H][L]$} & 16.7 & -1 & 311.5 \\
\hline 9509363 & {$[\mathrm{ZnOHL}] /[\mathrm{Zn}][H]^{1}[L]$} & 0.82 & -3 & 309.5 \\
\hline 1509361 & {$[\mathrm{CaL}] /[\mathrm{Ca}][\mathrm{L}]$} & 6.01 & -2 & 285.2 \\
\hline 4609361 & {$[M g L] /[M g][L]$} & 7.16 & -2 & 269.4 \\
\hline
\end{tabular}


occupy the coordination positions in the $\mathrm{CuH}_{2} \mathrm{~L}$ and CuHL species.

The values of $\mathrm{DCHA} / \mathrm{Fe}^{3+}$ are shown in Table 18. $\mathrm{FeHL}$, FeL, and $\mathrm{FeOHL}$ species were identified, and their stability constants were determined. This behavior is analogous to that observed for o,p-EDDHA/Fe ${ }^{3+}$.

\subsubsection{Equilibrium Constants for EDDS and IDHA}

As described above, new biodegradable chelating agents should be investigated to combat the environmental risks associated with the presence of recalcitrant chelating agents such as EDTA and o,oEDDHA, as well as their analogs, in the soil for long periods of time.

Equilibrium constants for IDHA and EDDS are shown in Tables 19 and 20, respectively. Equilibrium constants are bibliographically available [32-35,38,39]. Equilibrium constants for EDDS are very similar to those of EDTA since the same number (six) and type (two amine and four carboxylic groups) of donor groups are present in both chelating agents. However, only five donors groups are identified for IDHA, in which one basic amine group is absent when compared to EDTA.
Five protonation constants of IDHA were determined (see Table 19). The first protonation constant of IDHA corresponds with protonation of the tertiary amine group. The second and third protonation constants of IDHA correspond with protonation of the carboxylate groups. The two lowest protonation constants of IDHA involve protonation of the other carboxylate groups. The absence of one basic amine group significantly decreases IDHA/Fe ${ }^{3+}$ stability constants to approximately 9 units of log $\mathrm{K}$ with respect to those of EDTA/Fe ${ }^{3+}$, and a decrease of 20 units of log $\mathrm{K}$ compared with those of $0,0-\mathrm{EDDHA} / \mathrm{Fe}^{3+}$ is also noted.

\subsection{Practical Applications of Chemical Speciation Programs with Updated Databases}

Once both component and thermodynamic databases were updated with the described chelating agents and equilibrium constants, respectively, theoretical models were validated to ensure that theoretical chelate stability in their actual environments had been assessed [11]. Behavior of the $\mathrm{Fe}^{+3}$ chelates was examined in three agronomic situations. First, the theoretical model was constructed to simulate hydroponic conditions. Hoagland nutrient solution [24]

Table 20: Equilibrium constants for EDDS. Equilibrium constants are shown in terms of activity constants $\left(\mathrm{K}^{0}\right)$. Other mandatory parameters such as charge and Molecular Weight (MW) have to be entered in thermodynamic database

\begin{tabular}{|c|c|c|c|c|}
\hline \multicolumn{5}{|c|}{ EDDS } \\
\hline Specie ID\# & Specie Equilibrium & Ko & Charge & MW \\
\hline 3309391 & {$[H L] /[H][L]$} & 10.87 & -3 & 293.0 \\
\hline 3309392 & {$\left[H_{2} L\right] /[H]^{2}[L]$} & 18.33 & -2 & 294.0 \\
\hline 3309393 & {$\left[H_{3} L\right] /[H]^{3}[L]$} & 22.5 & -1 & 295.0 \\
\hline 3309394 & {$\left[H_{4} L\right] /[H]^{4}[L]$} & 25.66 & 0 & 296.0 \\
\hline 3309395 & {$\left[H_{5} L\right] /\left[H \Gamma^{5}[L]\right.$} & 26.95 & 1 & 297.0 \\
\hline 3309396 & {$\left[H_{6} L\right] /\left[H{ }^{6}[L]\right.$} & 28.72 & 2 & 298.0 \\
\hline 2819391 & {$[\mathrm{FeL}] /[\mathrm{Fe}][\mathrm{L}]$} & 23.68 & -1 & 347.9 \\
\hline 2319391 & {$[\mathrm{CuL}] /[\mathrm{Cu}][\mathrm{L}]$} & 20.46 & -2 & 355.6 \\
\hline 2319392 & {$[\mathrm{CuHL}][\mathrm{Cu}][\mathrm{H}][\mathrm{L}]$} & 24.39 & -1 & 356.6 \\
\hline 3309393 & {$\left[\mathrm{CuH}_{2} L\right] /[\mathrm{Cu}][H]^{2}[L]$} & 26.8 & 0 & 357.6 \\
\hline 2319394 & {$[\mathrm{CuOHL}] /[\mathrm{Cu}][\mathrm{H}]^{1}[\mathrm{~L}]$} & 8.81 & -3 & 354.6 \\
\hline 4709391 & {$[M n L] /[M n][L]$} & 10.77 & -2 & 347.0 \\
\hline 9509391 & {$[Z n L] /[Z n][L]$} & 15.34 & -2 & 357.4 \\
\hline 9509392 & {$[Z n H L] /[Z n][H][L]$} & 19.34 & -1 & 358.4 \\
\hline 1509391 & {$[\mathrm{CaL}] /[\mathrm{Ca}][\mathrm{L}]$} & 6.34 & -2 & 332.3 \\
\hline 4609391 & $[M g L] /[M g]][L]$ & 7.77 & -2 & 316.6 \\
\hline
\end{tabular}


was used, and $\mathrm{Fe}(\mathrm{OH})_{3}(\mathrm{amp})$ was introduced into the system for solubility control. The other models were constructed to predict the behavior of chelates in soil conditions. Two soil types with unlimited and limited $\mathrm{Cu}^{+2}$ availability were proposed to predict the stability of $\mathrm{Fe}^{+3}$ chelates with high and low $\mathrm{Cu}^{+2}$ levels in soil, respectively. The percentage of chelated $\mathrm{Fe}$ was obtained using the equilibrium speciation model MINTEQA2 [14], and most recently using the VMinteq program [15]. Free metal activity and species distribution were chosen as the parameters for defining $\mathrm{Fe}^{+3}$ chelate stability in agronomic conditions.

The proposed theoretical model was tested for all chelating agents by several authors. Thus, theoretical modeling for o,o-EDDHA, p,p-EDDHA, o,o-EDDMtxA, rac-0,o-EDDHA, meso-o,o-EDDHA, o,o-EDDH4MA, rac-o,o-EDDH4MA, meso-o,o-EDDHMA, 0,0EDDH5MA, and 0,0-EDDHSA has already been reported; it was found that $0,0-E D D H A$ and its analogs (exception for p,p-EDDHA and o,o-EDDMtxA) show comparable chelating abilities [13]. The theoretical models for 0,0-PDDHA, 0,0-BDDHA, and 0,0-XDDHA have been examined elsewhere [28]. It was found that when $\mathrm{pFe}$ is calculated using a nutrient solution composition, the differences among $\mathrm{pFe}$ values decreased, and o,o-XDDHA showed the highest affinity towards $\mathrm{Fe}^{3+}$; however, these values were independent of the length and complexity of the tether linking amino groups, and all chelating agents studied could be used as ferric chlorosis correctors, and they could be subsequently applied in soil/plant systems.

When o,p-EDDHA theoretical speciation was examined under hydroponic conditions [12,25], o,p$\mathrm{EDDHA} / \mathrm{Fe}^{3+}$ and $0, \mathrm{p}-\mathrm{EDDHA} / \mathrm{Zn}^{2+}$ result as effective iron and zinc sources at agronomic pHs. In soil conditions with limited $\mathrm{Cu}^{2+}$ availability, o,p$\mathrm{EDDHA} / \mathrm{Fe}^{3+}$ was stable; but when the soil contained large amounts of $\mathrm{Cu}^{2+}, \mathrm{Fe}^{3+}$ was displaced from the chelate.

Based on the theoretical modeling of the chelates, it was found that $\mathrm{DCHA} / \mathrm{Fe}^{3+}$ was superior to EDTA/Fe $\mathrm{Fe}^{3+}$ and o,p-EDDHA/Fe ${ }^{3+}$ as a ferric chelate to correct iron chlorosis for agronomic purposes [9]. We would have been unable to draw this conclusion if only the stability constants were analyzed.

$\mathrm{HBED} / \mathrm{Fe}^{3+}$ is the most stable chelate and $\mathrm{EDTA} / \mathrm{Fe}^{3+}$ the least stable among the three models. In the nutritive solution system, $\mathrm{Fe}$ (III) was chelated by HJB to a similar level as rac-0,0-EDDHA and meso-
0,0-EDDHA. In soils with limited $\mathrm{Cu}(\mathrm{II})$ levels, $\mathrm{HJB} / \mathrm{Fe}^{3+}$ chelate demonstrated similar stability levels to those in the model with unlimited $\mathrm{Cu}(\mathrm{II})$. It is also clear that for rac-0,0-EDDHA and meso-0,0-EDDHA, the main competitor is $\mathrm{Cu}$ (II) since in the limited $\mathrm{Cu}$ (II) model, the stability was considerably higher. While o,o-EDDHA and HJB may present similar stability levels in soil conditions, HJB demonstrates an advantage when high $\mathrm{Cu}$ (II) concentrations are present, given that that $\mathrm{Cu}$ (II) competition is not as important for HJB as for 0,0EDDHA [8].

Despite the fact that $\mathrm{IDHA} / \mathrm{Fe}^{3+}$ presents low stability and high reactivity in agronomic conditions since it is biodegradable, its use as an Fe fertilizer in hydroponics and fertirrigation should be considered [34].

\section{CONCLUSIONS}

Once the database is updated to contain new chelating agents with potential applications in agriculture and environmental industries, different scenarios can be considered. Theoretical models using any of the available chemical speciation programs (GEOCHEM, VMinteq, PhreeQC, etcetera) will be very useful for predicting the behavior of these chelating agents in different conditions. Currently, theoretical modeling is applied for chelating agents in order to determine their effectiveness as iron fertilizers in terms of their ability to maintain chelated $\mathrm{Fe}$ (III). The environmental geochemistry of chelating agents is not well-understood. Models such as the diffuse layer model (DLM) and the CD-MUSIC model (CDM) should be evaluated to describe the adsorption of these chelating agents to particle surfaces.

\section{ACKNOWLEDGEMENTS}

This work was supported by Projects AGL200763756 and AGL2010-18048 from Ministerio de Ciencia e Innovación (Spain), and by the European Science Foundation (ESF) within the framework of the ESF activity, 'The Functionality of Iron Minerals in Environmental Processes'. The authors thank Dr. M. A. Sierra and fertilizer companies, including PCC ADOB, Tradecorp, Syngenta Crop Protection, and DAABER, for providing us with synthetic chelating agents.

\section{SUPPORTING INFORMATION}

The supporting information can be downloaded from the journal website along with the article. 


\section{REFERENCES}

[1] Hernández-Apaolaza L, Lucena JJ. Influence of the soil/solution ratio. J Agric Food Chem 2011; 2493-500.

[2] Regulation (EC) No. 2003/2003. Official Journal of European Union 2003; 46.

[3] Regulation (EC) No 162/2007. Official Journal of European Union 2007; L51: 7-15.

[4] Commission Regulation (EU) No 137/2011. Official Journal of European Union 2011; L43: 1-8.

[5] Commission Regulation (EU) No 223/2012. Official Journal of European Union 2012; L75: 12-23.

[6] Sierra MA, Gómez-Gallego M, Alcázar R, Lucena JJ, Álvarez A, Yunta-Mezquita F. WO 02/00604 Patent 2002.

[7] Gómez-Gallego M, Sierra MA, Alcazar R, et al. Synthesis of o,p-EDDHA. J Agric Food Chem 2002; 50: 6395-9.

[8] López-Rayo S, Hernández D, Lucena JJ. Chemical evaluation. J Agric Food Chem 2009; 57: 8504-13.

[9] López-Rayo S, Hernández D, Lucena JJ. Synthesis. J Agric Food Chem 2010; 58: 7908-14.

[10] Nawrocki A, Stefaniak F, Mrozek-Niecko A, Olszewski R. Preparation o. PCT Int. Appl. WO 2009037235 A1 20090326, 2009.

[11] Yunta F, Sierra MA, Gómez-Gallego M, Alcázar R, GarcíaMarco S, Lucena JJ. Methodology. J Plant Nutr 2003; 26: 1995-8.

[12] Yunta F, García-Marco S, Lucena JJ. Theoretical. J Agric Food Chem 2003; 51: 5391-9. http://dx.doi.org/10.1021/jf034304r

[13] Yunta F, García-Marco S, Lucena JJ, Gómez-Gallego M, Alcazar R, Sierra MA. Chelating agents. Inorg Chem 2003; 42: $5412-21$ http://dx.doi.org/10.1021/ic034333

[14] Allison JD, Brown DS, Novo-Gradak KJ. MINTEQA2/ PRODEFA2. Version 3.0. User's Manual, Environmental Research Laboratory, U.S. Environmental Protection Agency: Washington, DC.1990.

[15] Gustafsson JP. Visual MINTEQ, Version 3.0 Kungl Tekniska Hogskolan (KTH), Div. of Land Water Resources, 2010, updated 06/21/06. http://www.Iwr.kth.se/English/OurSoftware/vminteq/.

[16] Parker DR, Norvell WA, Chaney RL. GEOCHEM-PC. In: Loeppert $\mathrm{RH}$, et al. Eds. Chemical equilibrium and reaction models. Soil Science Society of America, Special Publication 42, Madison 1995; pp. 253-69.

[17] Shaff JE, Shultz BA, Craft EJ, Clark RT, Kochian LV. GEOCHEM-EZ. Plant Soil 2010; 330: 207-14. http://dx.doi.org/10.1007/s11104-009-0193-9

[18] Parkhurst DL. User's guide to PHREEQC. U.S. Geological Survey Water-Resources Investigations Report 1995; 954227, $143 p$

[19] Álvarez-Fernández A, Sierra MA, Lucena JJ. Reactivity. Plant Soil 2002; 241: 129-37.

http://dx.doi.org/10.1023/A:1016012513044
[20] Hernández-Apaolaza L, Lucena JJ. Fe(III)-EDDHA. J Agric Food Chem 2001; 49: 5258-64.

[21] Hiemstra T, Van Riemsdijk WH. A Surface. J Colloid Interface Sci1996; 179: 488-508. http://dx.doi.org/10.1006/jcis.1996.0242

[22] Iglesias A, López R, Gondar D, Antelo J, Fiol S, Arce F. Adsorption of MCPA. Chemosphere 2010; 78: 1403-8. http://dx.doi.org/10.1016/i.chemosphere.2009.12.063

[23] Gustafsson JP, Dässman E, Bäckström M. Towards. Appl Geochem 2009; 454-62.

[24] Lindsay WL. Chemical Equilibrium in Soils, Wiley: New York 1979.

[25] López-Rayo S, Correas C, Lucena JJ. Novel. Chem Spec Bioav 2012; 24: 147-58.

[26] Martell AE, Motekaitis RJ. Determination. VCH: New York 1992.

[27] Bailey NA, Cummins D, McKenzie ED, Worthington JM. Iron. Inorg Chim Acta 1981; 50: 111.

http://dx.doi.org/10.1016/S0020-1693(00)83729-9

[28] Sierra MA, Gómez-Gallego M, Alcázar R, Lucena JJ, Yunta F, García-Marco S. 2004. Effect. Dalton Trans 2004; 3741-7. http://dx.doi.org/10.1039/b408730e

[29] Ma R, Motekaitis R, Martell AE. Stability. Inorg Chim Acta 1994; 224: 151-5. http://dx.doi.org/10.1016/0020-1693(94)04012-5

[30] L'Eplattenier F, Murase I, Martell AE. New multidentate ligands. JACS 1967; 89: 837. http://dx.doi.org/10.1021/ja00980a019

[31] Hyvönen H, Orama M, Saarinen H, Aksela R. Studies. Green Chem 2003; 5: 410-4.

[32] Mitschker A, Moritz RJ, Nawrocki A. Chelated plant micronutrients. European Patent 1411037 A1 20040421. 2004.

[33] Lucena JJ, Sentís JA, Villén M, Lao T, Pérez-Sáez M. Agron J 2008; 100: 813-8. http://dx.doi.org/10.2134/agronj2007.0257

[34] Villén M, García-Arsuaga M, Lucena JJ. Potential. J Agric Food Chem 2007; 55: 402-7.

[35] Rodríguez-Lucena $P$, Hernández-Apaolaza L, Lucena JJ. Comparison. J Plant Nutr Soil Sci 2010; 173: 120-6.

[36] Davies CW. Iron Association. Butterworhs, London 1962.

[37] Lucena JJ, García-Marco S, Yunta F, Hernández-Apaolaza L. Theoretical. In: Biogeochemistry of Chelating Agents, ACS Book Series, Springer Verlag: New York 2005; 348-65. http://dx.doi.org/10.1021/bk-2005-0910.ch021

[38] Pesonen H, Aksela R, Laasonen K. Density. J Mol Struct 2007; 804: 101-10.

[39] Orama M, Hyvonen H, Saarinen H, Aksela R. Complexation. J Chem Soc Dalton Trans 2002; 24: 4644-8. http://dx.doi.org/10.1039/b207777a 